Lumpy Price Adjustments: A Microeconometric Analysis

Emmanuel Dhyne, Catherine Fuss, Hashem Pesaran, Patrick Sevestre

April 2007

CWPE 0719 


\title{
Lumpy Price Adjustments: A Microeconometric Analysis*
}

\author{
Emmanuel Dhyne ${ }^{\dagger} \quad$ Catherine Fuss $^{\ddagger} \quad$ Hashem Pesaran ${ }^{\S}$ \\ Patrick Sevestreף
}

April 22, 2007

\begin{abstract}
This paper presents a simple model of state-dependent pricing that allows identification of the relative importance of the degree of price rigidity that is inherent to the price setting mechanism (intrinsic) and that which is due to the price's driving variables (extrinsic). Using two data sets consisting of a large fraction of the price quotes used to compute the Belgian and French CPI, we are able to assess the role of intrinsic and extrinsic price stickiness in explaining the occurrence and magnitude of price changes at the outlet level. We find that infrequent price changes are not necessarily associated with large adjustment costs. Indeed, extrinsic rigidity appears to be significant in many cases. We also find that asymmetry in the price adjustment could be due to trends in marginal costs and/or desired mark-ups rather than asymmetric cost of adjustment bands.
\end{abstract}

JEL Classifications: $C 51, C 81, D 21$.

Keywords: Sticky prices, nominal intrinsic and extrinsic rigidities, micro nonlinear panels

*The views expressed are those of the authors and do not necessarily reflect the views of the National Bank of Belgium or those of the Banque de France. We would like to thank the INS-NIS (Belgium) and the INSEE (France) for providing the micro price data. Preliminary versions of this paper have been presented at the 13th Panel Data conference, the 1st SOEGW conference, the 2006 NBB Colloquium and at workshops at the National Bank of Belgium, the Banque de France and the Magyar Nemzeti Bank. We would also like to thank the participants at these venues for their helpful comments. We are especially grateful to Luc Aucremanne, Agnes Csermely, Vassilis Hajivassiliou, Cheng Hsiao, Jerzy Konieczny, Hervé Le Bihan, Daniel Levy, and Rafaël Wouters for their comments on early drafts and to Frank Osaer for his technical assistance.

${ }^{\dagger}$ Banque Nationale de Belgique and Université de Mons-Hainaut.

†Banque Nationale de Belgique and Université Libre de Bruxelles.

$\S$ Cambridge University and University of Southern California.

๑Paris School of Economics, Un iversité Paris 1 - Panthéon Sorbonne and Banque de France. 


\section{Introduction}

Following the seminal contributions of Cecchetti (1986) on newspaper prices, Kashyap (1995) on catalog prices (both using US data), and Lach and Tsiddon (1992) on meat and wine prices in Israel, a recent wave of empirical research has provided new evidence on consumer and producer price stickiness at the micro level. Bils and Klenow (2004) and Klenow and Kryvstov (2005) provide studies on consumer prices in the US and Dhyne et al. (2006) give a synthesis of the recent studies carried out for the euro area countries. Studies of producer prices include Alvarez et al. (2006), Cornille and Dossche (2006), Loupias, Heckel and Sevestre (2007) and Sabbatini et al. (2005) among many others.

One of the main conclusions of these studies is the existence of a significant degree of heterogeneity in the degree of price flexibility across different product categories. Some products are characterized by a high frequency of price changes, with outlets reseting their prices almost on a continuous basis (for instance, oil products and perishable goods), whilst other product categories are characterized by a very low frequency of price changes (for instance, in some services). Aucremanne and Dhyne (2004) also document a high degree of heterogeneity in the duration of price spells (and hence in the frequency of price changes) even within relatively homogeneous product categories. Indeed, several studies have shown that the frequency of consumer price changes not only differs across product categories, but also varies across categories of retailers. ${ }^{1}$ Hyper and super-markets also tend to change their prices more frequently than local corner shops.

These studies are, however, silent as to the reasons for such infrequent price changes. A low frequency of price change has sometimes been taken as evidence of nominal or intrinsic price rigidity, namely price rigidity that is inherent to the price-setting mechanism. This ignores the role of extrinsic rigidity in price stickiness, namely the type of price rigidity that is induced by a low degree of volatility of either common or idiosyncratic shocks to the marginal cost and/or the desired mark-up. ${ }^{2}$ Indeed, infrequent price changes are not necessarily due to high cots of price adjustments (i.e. nominal or intrinsic rigidities). When marginal costs and other market conditions do not vary, firms have little or no incentive to change their prices. In this paper, we aim at identifying the respective contributions of intrinsic and extrinsic rigidities to the observed price stickiness. For that purpose, we develop a state dependent price-setting model, close in spirit to Cec-

\footnotetext{
${ }^{1}$ See Baudry et al. (2007), Fougère, Le Bihan and Sevestre (2007), Jonker, Blijenberg and Folkertsma (2004), and Veronese et al. (2005).

${ }^{2}$ Here we are adopting a terminology used in Altissimo, Erhmann and Smets (2006) to characterize the different sources of inflation persistence.
} 
chetti (1986), that relates price changes to the variations in an unobserved optimal price reflecting common and idiosyncratic movements in marginal costs and/or in the desired mark-up, but where price changes are subject to price adjustment costs. ${ }^{3}$ Compared to the existing literature, we argue and show that the frequency of price changes may be a poor indicator of intrinsic price rigidities. Our estimates reveal that the scarcity of price changes for some services in particular originates essentially from extrinsic rigidities rather than from high intrinsic rigidities.

The outline of the rest of the paper is as follows. We first present the theoretical model in Section 2. We then discuss the estimation procedure in Section 3. Section 4 describes the micro price data sets used and presents the estimation results. Section 5 concludes.

\section{A Canonical Model of Sticky Prices}

It is now a well-established stylized fact that most consumer prices remain unchanged for periods that can last several months (e.g. see Bils and Klenow, 2004, Dhyne et al., 2006, among many others). Indeed, for a number of reasons (physical menu costs, fear of consumer anger, etc.), retailers may be reluctant to immediately adjust their prices to changes in their environment (costs increases/decreases, demand variations, changes in local competition, etc.). Such a behavior can be modelled assuming fixed price adjustment costs that do not depend on the size of the price change, ${ }^{4}$ leading to an optimal price strategy of the $(s, S)$ variety. See, for example, Sheshinski and Weiss $(1977,1983)$, Cecchetti (1986), and Gertler and Leahy (2006).

A simple representation of this behavior can be written as:

$$
p_{i t}^{(j)}= \begin{cases}p_{i, t-1}^{(j)} & \text { if }\left|p_{i t}^{(j) *}-p_{i, t-1}^{(j)}\right| \leq c_{i t}^{(j)}, \\ p_{i t}^{(j) *} & \text { if }\left|p_{i t}^{(j) *}-p_{i, t-1}^{(j)}\right|>c_{i t}^{(j)}\end{cases}
$$

where $p_{i t}^{(j)}$ is the $(\log )$ observed price of a product $j$ in outlet $i$ at time $t, p_{i t}^{(j) *}$ is the $(\log )$ optimal price that would be set in the absence of any adjustment costs, and $c_{i t}^{(j)}$ denotes

\footnotetext{
${ }^{3}$ The use of state dependent price-setting rules by firms seem to be supported by surveys. Indeed, Fabiani et al. (2005) report that in the euro area $66 \%$ of firms consider pure or mixed state dependent pricing rules in order to decide when to change their prices.

${ }^{4}$ Several papers have found evidence of fixed physical menu costs of price adjustment (Levy et al., 1997, Zbaracki et al., 2004). However, Zbaracki et al. (2004) argue that, in addition to these fixed physical menu costs, managerial and customers costs are convex in the price change, while survey responses discussed in Blinder et al. (1998) suggest that price adjustment costs might be fixed.
} 
the thresholds beyond which outlets find it profitable to adjust their prices in response to a shock, i.e. the extent to which price changes are costly; $c_{i t}^{(j)}$ essentially represents the costs incurred by the outlet when changing its price. ${ }^{5}$ In what follows to simplify the notation we drop the superscript $j$ and continue to refer to $c_{i t}$ as the adjustment cost, although it is clear that $c_{i t}$ goes beyond physical menu cost (see below), and represents all types of costs associated with the price change by outlet $i$ in period $t$. We shall also refer to the condition

$$
\left|p_{i t}^{*}-p_{i, t-1}\right| \geq c_{i t},
$$

as the 'price change trigger' condition. The magnitude of $c_{i t}$ characterizes the extent of intrinsic price rigidity. The larger it is, the lower the likelihood of a price change in response to a given shock.

This model is very close in spirit to the econometric model proposed by Rosett (1959) for the analysis of frictions in yield changes. However, we depart from Rosett's model in that, in our model, the adjustment threshold, $c_{i t}$, only affects the decision to change prices but not the level of the newly set prices, $p_{i t}^{*}$. Indeed, we consider that when firms decide to adjust their prices, they fully adjust to the optimal price while in Rosett's model, agents are assumed to reduce the magnitude of their effective adjustment by the amount of the adjustment cost they incur. Denoting by $I(A)$ an indicator function that takes the value of unity if $A>0$ and zero otherwise, model (1), can be written as:

$$
\begin{aligned}
p_{i t}= & p_{i, t-1}+\left(p_{i t}^{*}-p_{i, t-1}\right) I\left(p_{i t}^{*}-p_{i, t-1}-c_{i t}\right) \\
& +\left(p_{i t}^{*}-p_{i, t-1}\right) I\left(p_{i, t-1}-p_{i t}^{*}-c_{i t}\right) .
\end{aligned}
$$

This formulation is reasonably general and allows the adjustment cost to vary both over time and across outlets. Assuming constant and identical adjustment costs might be considered as a too strong assumption since, as documented in Aucremanne and Dhyne (2004) and Fougère, Le Bihan and Sevestre (2007) among others, price setting can be strongly heterogeneous across outlets, even within relatively homogeneous product categories. At the outlet level, some price trajectories may be characterized by very frequent price changes, while others may be characterized by infrequent price changes. Moreover, as described in Campbell and Eden (2005), some price trajectories at the micro level exhibit long periods of price stability followed by periods of frenetic price changes. As noted by Caballero and Engel (2006), this pattern of price changes suggests that $c_{i t}$ is

\footnotetext{
${ }^{5}$ For the sake of simplifying notations, we will not, in the sequel, use anymore the index $j$ for products since we estimate this model for each product separately.
} 
best modelled as a stochastic process. Another argument for adopting such an approach lies in the synchronization of price changes within stores. Midrigan (2006) documents that a lot of price changes are particularly small compared to the average magnitude of price changes. ${ }^{6}$ Following Lach and Tsiddon (2005), he rationalizes these small price changes by the existence of economies of scales in price changes for multi-product sellers. This may be accounted for by allowing for some variability in adjustment costs.

As mentioned above, $c_{i t}$ is only partly determined by the narrow traditional notion of menu costs (the cost of changing posted prices, including managerial and decision costs), but it is also intended to reflect a broader notion of costs of price adjustments. For instance, the magnitude of $c_{i t}$ may reflect the specific marketing policy of outlets, regarding sales or promotions. They may also capture the degree of customers anger against price changes, as in Rotemberg (2003). If a firm fears to lose a significant fraction of its customers when it changes its prices, it will keep its prices constant as long as the expected loss induced by a non optimal price is smaller than the expected loss associated with customers anger. Interpreting the adjustment costs as a proxy of the importance of customer relationship instead of traditional price adjustment costs is supported by surveys on price setting behavior. Indeed, Fabiani et al. (2005) for the euro area, Aucremanne and Druant (2005) for Belgium or Loupias and Ricart (2006) for France, on the basis of surveys about firms' price setting behavior, indicate that a major source of price stickiness lies in customer relationships (existence of implicit or explicit contracts), while physical menu costs are not considered as a major source of nominal rigidity. ${ }^{7}$

Now, the question arises as whether we can also identify extrinsic rigidities, i.e. those corresponding to the low variability of the fundamentals underlying prices such as changes in marginal costs caused by input price variations or demand variations, changes in the mark-up caused by varying market competition, etc. Consider that, for a given product line, retailer $i$ that operates on a market characterized by imperfect competition sets optimally its price at its marginal cost, $M C_{i t}$, augmented by its desired mark-up rate $\left(M U_{i t}\right)$ :

$$
P_{i t}^{*}=M C_{i t} \times\left(1+M U_{i t}\right) .
$$

\footnotetext{
${ }^{6}$ Using US data, Midrigan (2006) indicates that $30 \%$ of the observed price changes are smaller than half of the average absolute size of price changes. For Belgium, $34 \%$ of the observed price changes fullfill a similar condition. This proportion is close to $50 \%$ in France.

${ }^{7}$ Although these studies relate to producer prices, one can expect these particular observations to be also relevant for consumer prices.
} 
Using logarithms, the (log) optimal price may be written as:

$$
p_{i t}^{*}=m c_{i t}+\mu_{i t}
$$

Unfortunately, despite their size and coverage, the data sets available on consumer prices do not provide any information on costs and demand conditions faced by outlets. In spite of this, it is possible, as we shall show below, to extract information on the probability distribution of $p_{i t}^{*}$, using a non-linear unobserved common factor model. To this end, we have decomposed the (unobserved) optimal price $p_{i t}^{*}$ as follows:

$$
p_{i t}^{*}=f_{t}+\mathbf{x}_{i t}^{\prime} \boldsymbol{\beta}+v_{i}+\varepsilon_{i t},
$$

where $f_{t}$ represents the unobserved common component of $p_{i t}^{*}, \mathbf{x}_{i t}$ is a vector of observable retail-specific variables, $v_{i}$ are retail-specific time-invariant unobservable effects, while $\varepsilon_{i t}$ accounts for firm-specific idiosyncratic shocks. The common component, $f_{t}$, can be viewed as the (log) producer price paid by all outlets, apart from a scaling constant. The remaining terms in (4) are intended to capture the differences in marginal costs and mark-ups across the outlets. The above decomposition also allows us to distinguish between extrinsic and intrinsic sources of price rigidities. Changes in the marginal costs as well as other changes in the market conditions (competition, demand variations) that are common to all outlets, as reflected in $f_{t}$, can be viewed, as a first source of extrinsic rigidity.

The variables $\mathbf{x}_{i t}$ are introduced to control for the possible effects of store type (such as hyper or supermarket versus corner shop) or geographical location (city centre or suburbs), and other observable characteristics on price setting behavior of the outlets. The retail-specific unobservable effects, $v_{i}$, account for the heterogeneity in the level of observed prices at the product category level that cannot be traced to observables (product differentiation and/or the ability of retailer $i$ to consistently price above or below the common component $f_{t}$, e.g. because of local competitive conditions). $\varepsilon_{i t}$ accounts for idiosyncratic shocks to marginal costs and/or to the desired mark-up that depend on some particular factors such as specific changes in (local) competition conditions, rebates on the wholesale price obtained by large retailer chains, management quality, quality of customer relations. This component also includes outlet specific seasonal patterns arising from specific sales and other forms of market promotions. The magnitude of idiosyncratic shocks, as measured by the standard deviation of $\varepsilon_{i t}$, say $\sigma_{\varepsilon}$, is then also informative about the extent of extrinsic rigidity. For example, everything else being equal, we would expect 
products with low estimates of $\sigma_{\varepsilon}$ to have also relatively low frequency of price changes. This factor may also be an important source of infrequent price changes if we consider the results reported in Fabiani et al. (2005), Aucremanne and Druant (2005) or Loupias and Ricart (2006). Indeed, these papers show that, in addition to customer relationship, what is considered as a major source of price rigidity by firms is the fact that their marginal costs are relatively stable. Finally, following Golosov and Lucas (2003), this idiosyncratic component might be a crucial factor in capturing the very diverse price dynamics that are observed even for relatively homogenous product categories. This point is illustrated in the price trajectories for oranges in Belgium and men's socks in France displayed in figures Figures 1.A and 1.B, respectively.

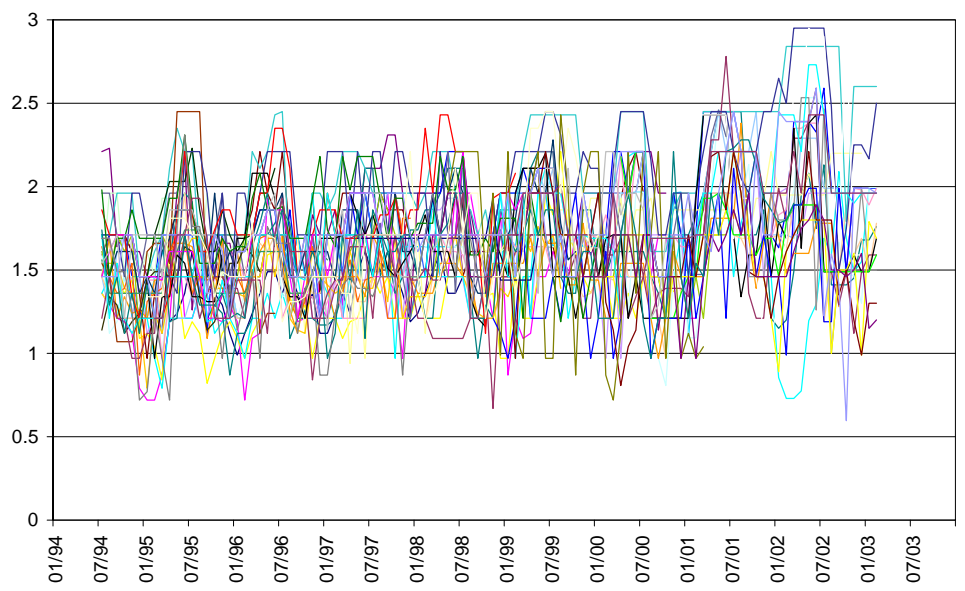

Figure 1.A. - 50 Price trajectories - Oranges (in EUR/Kg) - Belgian CPI

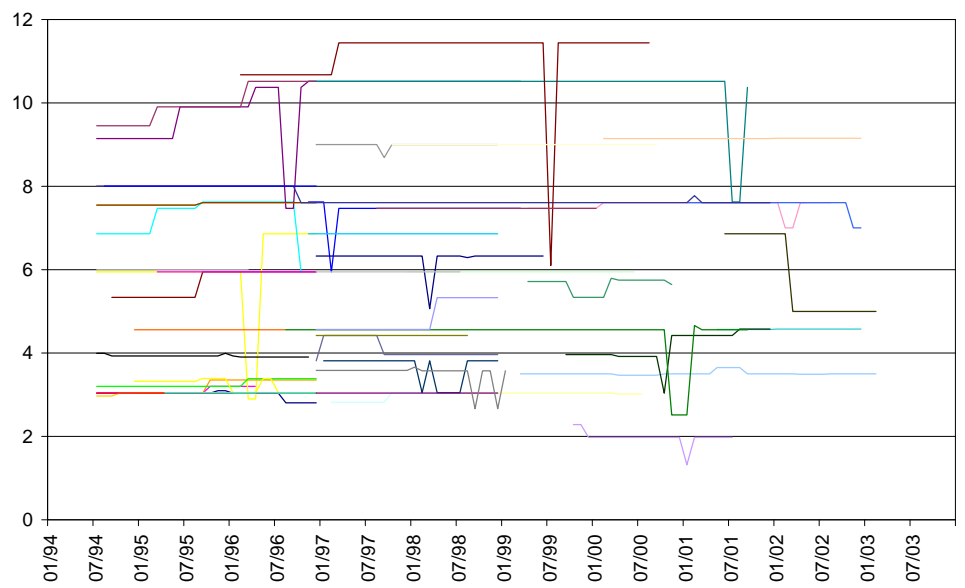

Figure 1.B - 50 Price trajectories - Men's socks (in EUR) - French CPI

Although our model is relatively close to the one presented for instance in Tsiddon (1993) or Ratfai (2006), we depart from the existing empirical literature in several ways. 
First, rather than using a proxy for the common component $f_{t}$ (a sectoral producer price index is often used in this respect; see Ratfai, 2006), we estimate it out of the micro price data. One important advantage of proceeding in this way is to ensure the coherency of this common component with the dynamics of micro price decisions as stated by our model.

Second, we also depart from the existing empirical literature in the information used in our estimation procedure. Most of the literature estimates state-dependent pricing model using binary response or duration models (Cecchetti, 1986, Aucremanne and Dhyne, 2005, Campbell and Eden, 2006, Fougère, Le Bihan and Sevestre, 2007, Ratfai, 2006) and therefore neglects the information contained in the magnitude of price changes. However, as we show below, this information is crucial in order to identify the volatility of the idiosyncratic shocks and for disentangling the idiosyncratic shocks (to marginal costs and/or desired mark-ups) from the stochastic price adjustment costs.

\subsection{Extensions to the basic model}

The above model can be generalized in a number of ways. Here, we discuss two important extensions.

\subsubsection{Gradual adjustment}

One important extension is to allow for only a partial adjustment of prices to their optimal values. While the basic model assumes that, once the retailers decide to adjust their prices, they fully adjust to the optimal price $p_{i t}^{*}$, retailers may possibly decide to proceed only with a partial adjustment of their prices, setting their new price $p_{i t}$ as $(1-\lambda) p_{i t}^{*}+\lambda p_{i, t-1}$, where $\lambda$ is the partial adjustment coefficient $(0 \leq \lambda<1)$. Such a partial adjustment process may be motivated on several grounds. First, uncertainty surrounding the evaluation of the size and source (common or idiosyncratic) of the shocks to the marginal cost and/or desired mark-up may lead firms to adopt a conservative attitude towards price changes. Indeed, competition on the product market may induce firms to proceed only to partial price adjustments in response to shocks, in order to keep their market shares when they do not know about their competitors' reaction. Secondly, under consumers' inattention (Levy et al., 2005), it may be more profitable for outlets to perform gradual adjustments to the optimal price level rather than a single large price change. Thirdly, if the information gathering process is costly as in Mankiw and Reis (2002), some firms may consider as more profitable to base their current price decision 
partly on past information.

In that case, the price change trigger condition becomes:

$$
\left|(1-\lambda) p_{i t}^{*}+\lambda p_{i, t-1}-p_{i, t-1}\right|>c_{i t}
$$

or, equivalently,

$$
(1-\lambda)\left|p_{i t}^{*}-p_{i, t-1}\right|>c_{i t}
$$

A non zero $\lambda$ parameter introduces an additional source of rigidity due to price level persistence, and accordingly adds a backward-looking component in the model.

\subsubsection{Asymmetric adjustment costs}

Another natural extension of the basic model is to allow for asymmetric price adjustments, by allowing the size of the adjustment costs for downward and upward price movements to be different. This is justified in theory where firms discount future profits, or if the profit function and the distribution of shocks themselves are asymmetric. Indeed, Aucremanne and Dhyne (2004) and Baudry et al. (2007), among others, have highlighted that price decreases are less frequently observed than price increases, especially in the service sector. This could result from asymmetric price adjustment costs and, more specifically, from stronger downward intrinsic rigidities (as discussed in Hall and Yates, 1998, and Yates, 1998). In order to test this assumption, one can extend our basic specification and write:

$$
\begin{aligned}
p_{i t}= & p_{i, t-1}+\left(p_{i t}^{*}-p_{i, t-1}\right) I\left(p_{i t}^{*}-p_{i, t-1}-c_{U i t}\right) \\
& +\left(p_{i t}^{*}-p_{i, t-1}\right) I\left(p_{i, t-1}-p_{i t}^{*}-c_{L i t}\right) .
\end{aligned}
$$

If $c_{L i t}>c_{U i t}$, this model will produce more price increases than price decreases, for given values of $f_{t}$. However, it is important to stress that asymmetric thresholds do not necessarily reflect the asymmetry in strictly defined adjustment costs. Other sources of asymmetry such as the asymmetry of the profit function, of the probability distribution of shocks or the fact that firms discount future profits, all could contribute to asymmetric price adjustments. The range of inaction will then be asymmetric even if price adjustment costs are similar upwards and downwards.

It is also worth mentioning that asymmetry in the thresholds of inaction is sufficient but not necessary for generating more price increases than price decreases. Our baseline model, with $c_{L i t}=c_{U i t}=c_{i t}$, will generate more price rises than price falls, so long as $f_{t}$ 
exhibits a positive drift, as in Ball and Mankiw (1994).

These are important extensions, but to keep the computations manageable, in the empirical section we shall focus on the symmetric case.

\section{Estimation of the Model}

One can combine equations (3) and (4) representing our baseline price-setting model into the following econometric representation:

$$
\begin{aligned}
p_{i t}-p_{i, t-1}= & \left(f_{t}+\mathbf{x}_{i t}^{\prime} \boldsymbol{\beta}+v_{i}+\varepsilon_{i t}-p_{i, t-1}\right) I\left(f_{t}+\mathbf{x}_{i t}^{\prime} \boldsymbol{\beta}+v_{i}+\varepsilon_{i t}-p_{i, t-1}-c_{i t}\right) \\
& +\left(f_{t}+\mathbf{x}_{i t}^{\prime} \boldsymbol{\beta}+v_{i}+\varepsilon_{i t}-p_{i, t-1}\right) I\left(p_{i, t-1}-f_{t}-\mathbf{x}_{i t}^{\prime} \boldsymbol{\beta}-v_{i}-\varepsilon_{i t}-c_{i t}\right) .
\end{aligned}
$$

There are essentially two groups of parameters to estimate in this model. First, the unobserved common components, $f_{t}$, which can also be viewed as unobserved time effects. Second, the other structural parameters: $c$ and $\sigma_{c}$ which respectively denote the mean and standard deviation of $c_{i t}, \sigma_{\varepsilon}$, the standard deviation of the idiosyncratic shocks $\varepsilon_{i t}$, $\sigma_{v}$, the standard deviation of the firm specific random effect, $v_{i}$, and $\boldsymbol{\beta}$, the parameters associated with the observed explanatory variables, $\mathbf{x}_{i t}$.

The estimation of the baseline model can be carried out in two ways. One can use an iterative procedure that combines the estimation of the $f_{t}$ 's using the cross-sectional dimension of the data with the maximum likelihood estimation of the remaining structural parameters, conditional on the first-stage estimate of $f_{t}$. Alternatively, one can use a standard maximum likelihood procedure, where the $f_{t}$ 's are estimated simultaneously with the other parameters. The two procedures lead to consistent estimates, provided $N$ and $T$ are sufficiently large. It is worthwhile noting that if $N$ is small, one would face the well-known incidental parameters problem: the bias in estimating $f_{t}$, due to the limited size of the cross-sectional dimension, would contaminate the other parameter estimates. In the alternative situation where $T$ happens to be small, the problem of the initial observation would then become an important issue. Therefore, our estimation procedure is essentially valid for relatively large $N$ and $T$. Fortunately, in our context, prices of most of the products we consider have been observed monthly over the period 1994:7 - 2003:2 (i.e. more than 100 months), and the number of outlets selling the various products we consider are also relatively large, being only slightly less tgab 300, both in Belgium and in France. 


\subsection{Estimation of $f_{t}$ using cross-cectional averages}

As mentioned above, $f_{t}$ is in practice an unobserved time effect that needs to be estimated along with the other unknown parameters. It reflects the common component in the marginal cost and desired mark-up for each particular product for which we estimate the model. Thanks to the very large size and high degree of disaggregation of our data, we can split our data sets according to a very detailed definition of the products while keeping, at the same time, a large number of price trajectories in the sub-samples to be analyzed.

Moreover, because we are able to consider precisely defined types of products sold in a particular outlet, it is reasonable to assume that any remaining cross-sectional heterogeneity in the price level can be modelled through the observable outlet-specific characteristics, $\mathbf{x}_{i t}$, and through random specific effects (accounting for outlets unobserved characteristics). Accordingly, we assume that, conditional on $\mathbf{h}_{i t}=\left(f_{t}, \mathbf{x}_{i t}^{\prime}, p_{i, t-1}\right)^{\prime},\left(c_{i t}, v_{i}, \varepsilon_{i t}\right)^{\prime}$ are distributed independently across $i$, and that $c_{i t}$ and $\varepsilon_{i t}$ are serially uncorrelated. Due to the non-linear nature of the pricing process and to make the analysis tractable, we shall also assume that

$$
\left(\begin{array}{c}
c_{i t} \\
v_{i} \\
\varepsilon_{i t}
\end{array}\right) \mid \mathbf{h}_{i t} \backsim \text { i.i.d.N }\left(\left(\begin{array}{c}
c \\
0 \\
0
\end{array}\right),\left(\begin{array}{ccc}
\sigma_{c}^{2} & 0 & 0 \\
0 & \sigma_{v}^{2} & 0 \\
0 & 0 & \sigma_{\varepsilon}^{2}
\end{array}\right)\right) .
$$

The assumption of zero covariances across the errors is made for convenience and can be relaxed.

Before discussing the derivation of $f_{t}$ we state the following lemma, established in the Appendix, which provides a few results needed below.

Lemma 1 Suppose that $y \backsim N\left(\mu, \sigma^{2}\right)$ then

$$
\begin{gathered}
E[y I(y+a)]=\sigma \phi\left(\frac{a+\mu}{\sigma}\right)+\mu \Phi\left(\frac{a+\mu}{\sigma}\right), \\
E\left[\phi\left(\frac{y+a}{b}\right)\right]=\frac{b}{\sqrt{b^{2}+\sigma^{2}}} \phi\left(\frac{a+\mu}{\sqrt{b^{2}+\sigma^{2}}}\right), \\
E_{y}\left[\Phi\left(\frac{y+a}{b}\right)\right]=\Phi\left(\frac{a+\mu}{\sqrt{b^{2}+\sigma^{2}}}\right),
\end{gathered}
$$

where $\phi(\cdot)$ and $\Phi(\cdot)$ are, respectively, the density and the cumulative distribution function of the standard normal variate, and $I(A)$ is the indicator function defined above. 
Let

$$
d_{i t}=f_{t}+\mathbf{x}_{i t}^{\prime} \boldsymbol{\beta}-p_{i, t-1}, \quad \xi_{i t}=v_{i}+\varepsilon_{i t} \backsim N\left(0, \sigma_{\xi}^{2}\right),
$$

and note that $\sigma_{\xi}^{2}=\sigma_{v}^{2}+\sigma_{\varepsilon}^{2}$. Consider now the baseline model, (6), and using the above, write it as

$$
\Delta p_{i t}=\left(d_{i t}+\xi_{i t}\right) I\left(d_{i t}+\xi_{i t}-c_{i t}\right)+\left(d_{i t}+\xi_{i t}\right) I\left(-d_{i t}-\xi_{i t}-c_{i t}\right)
$$

or

$$
\Delta p_{i t}=\left(d_{i t}+\xi_{i t}\right)+\left(d_{i t}+\xi_{i t}\right)\left[I\left(d_{i t}+\xi_{i t}-c_{i t}\right)-I\left(d_{i t}+\xi_{i t}+c_{i t}\right)\right] .
$$

Denote the unknown parameters of the model by $\boldsymbol{\theta}=\left(c, \boldsymbol{\beta}^{\prime}, \sigma_{c}^{2}, \sigma_{v}^{2}, \sigma_{\varepsilon}^{2}\right)^{\prime}$, and note that

$$
E\left(\Delta p_{i t} \mid \mathbf{h}_{i t}, \boldsymbol{\theta}\right)=d_{i t}+g_{i t},
$$

where $g_{i t}=g_{1, i t}+g_{2, i t}$, with

$$
g_{1, i t}=d_{i t} E\left[I\left(d_{i t}+\xi_{i t}-c_{i t}\right)-I\left(d_{i t}+\xi_{i t}+c_{i t}\right) \mid \mathbf{h}_{i t}, \boldsymbol{\theta}\right],
$$

and

$$
g_{2, i t}=E\left[\xi_{i t} I\left(d_{i t}+\xi_{i t}-c_{i t}\right)-\xi_{i t} I\left(d_{i t}+\xi_{i t}+c_{i t}\right) \mid \mathbf{h}_{i t}, \boldsymbol{\theta}\right] .
$$

Also, under our assumptions

$$
\left(\begin{array}{c}
c_{i t} \\
\xi_{i t}
\end{array}\right) \mid \mathbf{h}_{i t} \backsim \text { i.i.d.N }\left(\left(\begin{array}{c}
c \\
0
\end{array}\right),\left(\begin{array}{cc}
\sigma_{c}^{2} & 0 \\
0 & \sigma_{v}^{2}+\sigma_{\varepsilon}^{2}
\end{array}\right)\right) \text {. }
$$

It is easily seen that

$$
\begin{aligned}
& E\left[I\left(d_{i t}+\xi_{i t}-c_{i t}\right)-I\left(d_{i t}+\xi_{i t}+c_{i t}\right) \mid \mathbf{h}_{i t}, \boldsymbol{\theta}\right] \\
= & \Phi\left(\frac{d_{i t}-c}{\sqrt{\sigma_{c}^{2}+\sigma_{\xi}^{2}}}\right)-\Phi\left(\frac{d_{i t}+c}{\sqrt{\sigma_{c}^{2}+\sigma_{\xi}^{2}}}\right)
\end{aligned}
$$

Using the results in Lemma 3.1 and noting that $\xi_{i t} \mid \mathbf{h}_{i t}, \boldsymbol{\theta} \backsim N\left(0, \sigma_{\xi}^{2}\right)$, then

$$
E\left[\xi_{i t} I\left(d_{i t}+\xi_{i t}-c_{i t}\right) \mid \mathbf{h}_{i t}, \boldsymbol{\theta}, c_{i t}\right]=\sigma_{\xi} \phi\left(\frac{d_{i t}-c_{i t}}{\sigma_{\xi}}\right)
$$


Hence, taking expectations with respect to $c_{i t}$, we have

$$
E\left[\xi_{i t} I\left(d_{i t}+\xi_{i t}-c_{i t}\right) \mid \mathbf{h}_{i t}, \boldsymbol{\theta}\right]=\sigma_{\xi} E\left[\phi\left(\frac{d_{i t}-c_{i t}}{\sigma_{\xi}}\right) \mid \mathbf{h}_{i t}, \boldsymbol{\theta}\right] .
$$

Again using the results in Lemma 3.1 we have

$$
E\left[\phi\left(\frac{d_{i t}-c_{i t}}{\sigma_{\xi}}\right) \mid \mathbf{h}_{i t}, \boldsymbol{\theta}\right]=\frac{\sigma_{\xi}}{\sqrt{\sigma_{c}^{2}+\sigma_{\xi}^{2}}} \phi\left(\frac{d_{i t}-c}{\sqrt{\sigma_{c}^{2}+\sigma_{\xi}^{2}}}\right)
$$

and therefore,

$$
E\left[\xi_{i t} I\left(d_{i t}+\xi_{i t}-c_{i t}\right) \mid \mathbf{h}_{i t}, \boldsymbol{\theta}\right]=\frac{\sigma_{\xi}^{2}}{\sqrt{\sigma_{c}^{2}+\sigma_{\xi}^{2}}} \phi\left(\frac{d_{i t}-c}{\sqrt{\sigma_{c}^{2}+\sigma_{\xi}^{2}}}\right)
$$

Similarly,

$$
E\left[\xi_{i t} I\left(d_{i t}+\xi_{i t}+c_{i t}\right) \mid \mathbf{h}_{i t}, \boldsymbol{\theta}\right]=\frac{\sigma_{\xi}^{2}}{\sqrt{\sigma_{c}^{2}+\sigma_{\xi}^{2}}} \phi\left(\frac{d_{i t}+c}{\sqrt{\sigma_{c}^{2}+\sigma_{\xi}^{2}}}\right)
$$

Collecting the various results we obtain

$$
g_{1, i t}=d_{i t}\left[\Phi\left(\frac{d_{i t}-c}{\sqrt{\sigma_{c}^{2}+\sigma_{\xi}^{2}}}\right)-\Phi\left(\frac{d_{i t}+c}{\sqrt{\sigma_{c}^{2}+\sigma_{\xi}^{2}}}\right)\right]
$$

and

$$
g_{2, i t}=\frac{\sigma_{\xi}^{2}}{\sqrt{\sigma_{c}^{2}+\sigma_{\xi}^{2}}}\left[\phi\left(\frac{d_{i t}-c}{\sqrt{\sigma_{c}^{2}+\sigma_{\xi}^{2}}}\right)-\phi\left(\frac{d_{i t}+c}{\sqrt{\sigma_{c}^{2}+\sigma_{\xi}^{2}}}\right)\right] .
$$

Note that $g_{1, i t}$ and $g_{2, i t}$ are non-linear functions of $f_{t}$ and depend on $i$ only through the observable, $p_{i, t-1}$ and $\mathbf{x}_{i t}$. It is therefore possible to compute $f_{t}$ for each $t$ in terms of $p_{i, t-1}, \mathbf{x}_{i t}$ and $\boldsymbol{\theta}$. Then, following Pesaran (2006), the cross-sectional average estimator of $f_{t}$, denoted by $\tilde{f}_{t}$, can be obtained as the solution to the following non-linear equation

$$
\bar{p}_{t}=\tilde{f}_{t}+\overline{\mathbf{x}}_{t}^{\prime} \boldsymbol{\beta}+\bar{g}_{t}\left(\tilde{f}_{t}\right)
$$

where

$$
\bar{p}_{t}=\sum_{i=1}^{N} w_{i t} p_{i t}, \overline{\mathbf{x}}_{t}=\sum_{i=1}^{N} w_{i t} \mathbf{x}_{i t} \text {, and } \bar{g}_{t}\left(f_{t}\right)=\sum_{i=1}^{N} w_{i t} g_{i t}
$$


and $\left\{w_{i t}, i=1,2, . ., N\right\}$ represent a predetermined set of weights such that

$$
w_{i t}=O\left(N^{-1}\right), \text { and } \sum_{i=1}^{N} w_{i t}^{2}=O\left(N^{-1}\right) .
$$

For a given value of $\boldsymbol{\theta}$ and each $t,(7)$ provides a non-linear function in $\tilde{f}_{t}$. This equation clearly shows that unlike the linear models considered in Pesaran (2006), here the solution to the common component $f_{t}$ does not reduce to an average of (log) prices. In particular, $\tilde{f}_{t}$ also accounts for the dynamic feature of the price-setting behavior through the $\bar{g}_{t}$ component, which depends on $p_{i, t-1}$. Equation (7) has a unique solution as long as $c>0$. A proof is provided in Appendix A. It is also easily seen that under the cross-sectional independence of $v_{i}$ and $\varepsilon_{i t}, \bar{g}_{t}\left(f_{t}\right) \rightarrow E\left(g_{i t}\right)$ and $\tilde{f}_{t}-f_{t} \stackrel{p}{\rightarrow} 0$, as $N \rightarrow \infty .^{8}$

\subsection{Conditional likelihood estimation with no individual effects}

In this section, we derive the maximum likelihood estimation of the structural parameters, $\boldsymbol{\theta}$, conditional on $f_{t}$ and assuming there are no firm-specific effects, so that $\sigma_{v}^{2}=0$, and hence in this case $\boldsymbol{\theta}=\left(c, \boldsymbol{\beta}^{\prime}, \sigma_{c}^{2}, \sigma_{\varepsilon}^{2}\right)^{\prime}$. Given the distributional assumptions stated in Section 3.1, and defining $\zeta_{i t}$ as $c_{i t}-c$, our baseline model can be rewritten as

$$
\Delta p_{i t}=d_{i t}+\varepsilon_{i t}+\left(d_{i t}+\varepsilon_{i t}\right)\left\{I\left[d_{i t}+\varepsilon_{i t}-\zeta_{i t}-c\right]-I\left[d_{i t}+\varepsilon_{i t}+\zeta_{i t}+c\right]\right\}
$$

where

$$
\left(\begin{array}{c}
\zeta_{i t} \\
\varepsilon_{i t}
\end{array}\right) \backsim i i d N\left(\left(\begin{array}{c}
0 \\
0
\end{array}\right),\left(\begin{array}{cc}
\sigma_{c}^{2} & 0 \\
0 & \sigma_{\varepsilon}^{2}
\end{array}\right)\right) \text {, for } i=1,2, \ldots, N ; t=1,2, \ldots, T \text {. }
$$

Equivalently

$$
\Delta p_{i t}=d_{i t}+\varepsilon_{i t}+\left(d_{i t}+\varepsilon_{i t}\right)\left\{I\left[d_{i t}-c+\varepsilon_{1 i t}\right]-I\left[d_{i t}+c+\varepsilon_{2 i t}\right]\right\},
$$

where

$$
\varepsilon_{1 i t}=\varepsilon_{i t}-\zeta_{i t}, \varepsilon_{2 i t}=\varepsilon_{i t}+\zeta_{i t},
$$

${ }^{8}$ For the sake of simplicity, we assume here that the panel data sample is balanced: all outlets are observed over the full time period. This is not the case in practice. However, the result can be easily generalized to unbalanced panels assuming that $N_{t} \rightarrow \infty$ for each $t$ (see the Appendix A). 
with

$$
\left(\begin{array}{c}
\varepsilon_{1 i t} \\
\varepsilon_{2 i t} \\
\varepsilon_{i t}
\end{array}\right) \sim i i d N\left(\left(\begin{array}{l}
0 \\
0 \\
0
\end{array}\right),\left(\begin{array}{ccc}
\sigma_{\varepsilon}^{2}+\sigma_{c}^{2} & \sigma_{\varepsilon}^{2}-\sigma_{c}^{2} & \sigma_{\varepsilon}^{2} \\
. & \sigma_{\varepsilon}^{2}+\sigma_{c}^{2} & \sigma_{\varepsilon}^{2} \\
. & \cdot & \sigma_{\varepsilon}^{2}
\end{array}\right)\right) \text {, for } i=1,2, \ldots, N ; t=1,2, \ldots, T
$$

Let

$$
\begin{aligned}
& \tau_{1 i t}=\left\{\begin{array}{c}
1 \text { if } \Delta p_{i t}=0 \text { for } i=1,2, \ldots, N \text { and } t=1,2, \ldots, T, \\
0 \text { otherwise }
\end{array}\right. \\
& \tau_{2 i t}=\left\{\begin{array}{c}
1 \text { if } \Delta p_{i t}>0 \text { for } i=1,2, \ldots, N \text { and } t=1,2, \ldots, T, \\
0 \text { otherwise }
\end{array}\right. \\
& \tau_{3 i t}=\left\{\begin{array}{c}
1 \text { if } \Delta p_{i t}<0 \text { for } i=1,2, \ldots, N \text { and } t=1,2, \ldots, T, \\
0 \text { otherwise }
\end{array}\right.
\end{aligned}
$$

Then conditional on $f_{t}, t=1,2, \ldots, T$ and the initial value $p_{i 0}$, the log-likelihood function of the model for each $i$ can be written as

$$
\begin{aligned}
L_{i}(\boldsymbol{\theta} \mid \mathbf{f})= & \operatorname{Pr}\left(\Delta p_{i 1} \mid p_{i 0}\right) \operatorname{Pr}\left(\Delta p_{i 2} \mid p_{i 0}, p_{i 1}\right) \\
& \times \operatorname{Pr}\left(\Delta p_{i, T} \mid p_{i 0}, p_{i 1}, \ldots, p_{i, T-1}\right) \times \operatorname{Pr}\left(p_{i 0}\right)
\end{aligned}
$$

where $\mathbf{f}=\left(f_{1}, f_{2}, \ldots, f_{T}\right)^{\prime}$. In view of the first-order Markovian property of the model we have

$$
\begin{aligned}
L_{i}(\boldsymbol{\theta} \mid \mathbf{f})= & \operatorname{Pr}\left(\Delta p_{i 1} \mid p_{i 0}\right) \operatorname{Pr}\left(\Delta p_{i 2} \mid p_{i 1}\right) \\
& \times \operatorname{Pr}\left(\Delta p_{i, T} \mid p_{i, T-1}\right) \times \operatorname{Pr}\left(p_{i 0}\right) .
\end{aligned}
$$

When $T$ is small, the contribution of $\operatorname{Pr}\left(p_{i 0}\right)$ could be important. In what follows we assume that $p_{i 0}$ is given and $T$ reasonably large so that the contribution of the initial observations to the log-likelihood function can be ignored.

To derive $\operatorname{Pr}\left(\Delta p_{i t} \mid p_{i, t-1}, f_{t}\right)$ we distinguish between cases where $\Delta p_{i t}=0, \Delta p_{i t}>0$ and $\Delta p_{i t}<0$, noting that

$$
\begin{aligned}
& \operatorname{Pr}\left(\Delta p_{i t} \mid \Delta p_{i t}=0, p_{i, t-1}, f_{t}\right)=\operatorname{Pr}\left(\varepsilon_{1 i t} \leq c-d_{i t} ; \varepsilon_{2 i t} \geq-c-d_{i t}\right) \\
= & \operatorname{Pr}\left(\varepsilon_{1 i t} \leq c-d_{i t}\right)-\operatorname{Pr}\left(\varepsilon_{1 i t} \leq c-d_{i t} ; \varepsilon_{2 i t} \leq-c-d_{i t}\right) \\
= & \Phi\left(\frac{c-d_{i t}}{\sqrt{\sigma_{\varepsilon}^{2}+\sigma_{c}^{2}}}\right)-\Phi_{2}\left(\frac{c-d_{i t}}{\sqrt{\sigma_{\varepsilon}^{2}+\sigma_{c}^{2}}} ; \frac{-c-d_{i t}}{\sqrt{\sigma_{\varepsilon}^{2}+\sigma_{c}^{2}}} ; \frac{\sigma_{\varepsilon}^{2}-\sigma_{c}^{2}}{\sigma_{\varepsilon}^{2}+\sigma_{c}^{2}}\right)=\pi_{1 i t},
\end{aligned}
$$


where $\Phi_{2}(x ; y ; \rho)$ is the cumulative distribution function of the standard bivariate normal. Similarly

$$
\begin{aligned}
& \operatorname{Pr}\left(\Delta p_{i t} \mid \Delta p_{i t}>0, p_{i, t-1}, f_{t}\right)=\operatorname{Pr}\left(\varepsilon_{i t}=\Delta p_{i t}-d_{i t}\right) \operatorname{Pr}\left(\varepsilon_{1 i t} \geq c-d_{i t} ; \varepsilon_{2 i t}>-c-d_{i t} \mid \varepsilon_{i t}\right) \\
= & \frac{1}{\sigma_{\varepsilon}} \phi\left(\frac{\Delta p_{i t}-d_{i t}}{\sigma_{\varepsilon}}\right)\left[\Phi\left(\frac{-c+\Delta p_{i t}}{\sigma_{c}}\right)-\Phi\left(\frac{-c-\Delta p_{i t}}{\sigma_{c}}\right)\right]=\pi_{2 i t},
\end{aligned}
$$

and

$$
\begin{aligned}
& \operatorname{Pr}\left(\Delta p_{i t} \mid \Delta p_{i t}<0, p_{i, t-1}, f_{t}\right)=\operatorname{Pr}\left(\varepsilon_{i t}=\Delta p_{i t}-d_{i t}\right) \operatorname{Pr}\left(\varepsilon_{1 i t}<c-d_{i t} ; \varepsilon_{2 i t} \leq-c-d_{i t} \mid \varepsilon_{i t}\right) \\
= & \frac{1}{\sigma_{\varepsilon}} \phi\left(\frac{\Delta p_{i t}-d_{i t}}{\sigma_{\varepsilon}}\right)\left[\Phi\left(\frac{-c-\Delta p_{i t}}{\sigma_{c}}\right)-\Phi\left(\frac{-c+\Delta p_{i t}}{\sigma_{c}}\right)\right]=\pi_{3 i t} .
\end{aligned}
$$

Hence

$$
\ell(\boldsymbol{\theta}, \mathbf{f})=\sum_{i=1}^{N} \ln L_{i}(\boldsymbol{\theta}, \mathbf{f})=\sum_{i=1}^{N} \sum_{t=1}^{T}\left[\tau_{1 i t} \ln \left(\pi_{1 i t}\right)+\tau_{2 i t} \ln \left(\pi_{2 i t}\right)+\tau_{3 i t} \ln \left(\pi_{3 i t}\right)\right]
$$

The ML estimator of $\boldsymbol{\theta}$ is given by

$$
\hat{\boldsymbol{\theta}}_{M L}(\mathbf{f})=\arg \max _{\boldsymbol{\theta}} \ell(\boldsymbol{\theta}, \mathbf{f})
$$

and for $N$ and $T$ sufficiently large we have:

$$
\sqrt{N T}\left(\hat{\boldsymbol{\theta}}_{M L}(\mathbf{f})-\boldsymbol{\theta}\right) \stackrel{a}{\sim} N\left(0, \mathbf{V}_{\boldsymbol{\theta}}\right),
$$

where $\mathbf{V}_{\boldsymbol{\theta}}$ is the asymptotic variance of the ML estimator and can be estimated consistently using the second derivatives of the log likelihood function.

Remark 1 In the case where $f_{t}, t=1,2, \ldots, T$ are estimated, the $M L$ estimators will continue to be consistent as both $N$ and $T$ tend to infinity. However, the asymptotic distribution of the ML estimator is likely to be subject to the generated regressor problem. The importance of the generated regressor problem in the present application could be investigated using a bootstrap procedure.

\subsection{Conditional likelihood estimation with random effects}

Consider now the random effects specification where $p_{i t}^{*}=f_{t}+\mathbf{x}_{i t}^{\prime} \boldsymbol{\beta}+v_{i}+\varepsilon_{i t}$, and note that

$$
\operatorname{Cov}\left(p_{i t}^{*}, p_{i t^{\prime}}^{*} \mid \mathbf{x}_{i t}, \mathbf{x}_{i t^{\prime}}\right)=\sigma_{v}^{2} \text { for all } t \text { and } t^{\prime}, t \neq t^{\prime}
$$


Under this model, the probability of no price change in a given period, conditional on the previous price, $p_{i, t-1}$, will not be independent of episodes of no price changes in the past. So we need to consider the joint probability distribution of successive unchanged prices. For example, suppose that prices for outlet $i$ have remained unchanged over the period $t$ and $t+1$, then the relevant joint events of interest are

$$
\mathcal{A}_{i t}:\left\{-c-\zeta_{i t}-d_{i t} \leq \varepsilon_{i t}+v_{i} \leq c+\zeta_{i t}-d_{i t}\right\},
$$

and

$$
\mathcal{A}_{i, t+1}:\left\{-c-\zeta_{i, t+1}-d_{i, t+1} \leq \varepsilon_{i, t+1}+v_{i} \leq c+\zeta_{i t}-d_{i, t+1}\right\}
$$

An explicit derivation of the joint distribution of $A_{i t}$ and $A_{i t+1}$ would seem rather difficult. An alternative strategy is to use the conditional independence property of successive price changes, and note that for each $i$, and conditional on $\mathbf{v}=\left(v_{1}, v_{2}, \ldots, v_{N}\right)^{\prime}$ and $\mathbf{f}$, the likelihood function will be given by

$$
L(\boldsymbol{\theta}, \mathbf{v}, \mathbf{f})=\prod_{i=1}^{N} \prod_{t=1}^{T}\left[\pi_{1 i t}\left(v_{i}\right)\right]^{\tau_{1 i t}}\left[\pi_{2 i t}\left(v_{i}\right)\right]^{\tau_{2 i t}}\left[\pi_{3 i t}\left(v_{i}\right)\right]^{\tau_{2 i t}},
$$

where

$$
\begin{aligned}
& \pi_{1 i t}\left(v_{i}, f_{t}\right)=\Phi\left(\frac{c-v_{i}-d_{i t}}{\sqrt{\sigma_{\varepsilon}^{2}+\sigma_{c}^{2}}}\right)-\Phi_{2}\left(\frac{c-v_{i}-d_{i t}}{\sqrt{\sigma_{\varepsilon}^{2}+\sigma_{c}^{2}}} ; \frac{-c-v_{i}-d_{i t}}{\sqrt{\sigma_{\varepsilon}^{2}+\sigma_{c}^{2}}} ; \frac{\sigma_{\varepsilon}^{2}-\sigma_{c}^{2}}{\sigma_{\varepsilon}^{2}+\sigma_{c}^{2}}\right), \\
& \pi_{2 i t}\left(v_{i}, f_{t}\right)=\frac{1}{\sigma_{\varepsilon}} \phi\left(\frac{\Delta p_{i t}-v_{i}-d_{i t}}{\sigma_{\varepsilon}}\right)\left[\Phi\left(\frac{-c+\Delta p_{i t}}{\sigma_{c}}\right)-\Phi\left(\frac{-c-\Delta p_{i t}}{\sigma_{c}}\right)\right]
\end{aligned}
$$

and

$$
\pi_{3 i t}\left(v_{i}, f_{t}\right)=\frac{1}{\sigma_{\varepsilon}} \phi\left(\frac{\Delta p_{i t}-v_{i}-d_{i t}}{\sigma_{\varepsilon}}\right)\left[\Phi\left(\frac{-c-\Delta p_{i t}}{\sigma_{c}}\right)-\Phi\left(\frac{-c+\Delta p_{i t}}{\sigma_{c}}\right)\right] .
$$

The random effects can now be integrated out with respect to the distribution of $v_{i}$ [assuming $v_{i} \sim N\left(0, \sigma_{v}^{2}\right)$, for example] and then the integrated log-likelihood function, $E_{\mathbf{v}}[\ell(\boldsymbol{\theta}, \mathbf{v}, \mathbf{f})]$, maximized with respect to $\boldsymbol{\theta} \cdot{ }^{9}$

\footnotetext{
${ }^{9} \mathrm{~A}$ further extension of the model would consist of including also a firm specific effect into the menu cost. However, the estimation of this model would then requires a double integration with respect to the distribution of the two individual effects.
} 


\subsection{Full maximum likelihood estimation}

In the case where $N$ and $T$ are sufficiently large, the incidental parameters problem does not arise and the effects of the initial distributions, $\operatorname{Pr}\left(p_{i 0}\right)$, on the likelihood function can be ignored. Then, the maximum likelihood estimators of $\boldsymbol{\theta}$ and $\mathbf{f}$ can be obtained as the solution to the following maximization problem:

$$
\left(\hat{\mathbf{f}}_{M L}, \widehat{\boldsymbol{\theta}}_{M L}\right)=\arg \max _{\mathbf{f}, \boldsymbol{\theta}} \sum_{t=1}^{T} \sum_{i=1}^{N}\left[\tau_{1 i t} \ln \left(\pi_{1 i t}\right)+\tau_{2 i t} \ln \left(\pi_{2 i t}\right)+\tau_{3 i t} \ln \left(\pi_{3 i t}\right)\right]
$$

Note that for a given value of $\boldsymbol{\theta}$ the ML estimator of $f_{t}$ can be obtained as

$$
\hat{f}_{t}(\boldsymbol{\theta})=\arg \max _{f_{t}} \sum_{i=1}^{N}\left[\tau_{1 i t} \ln \left(\pi_{1 i t}\right)+\tau_{2 i t} \ln \left(\pi_{2 i t}\right)+\tau_{3 i t} \ln \left(\pi_{3 i t}\right)\right],
$$

and will be consistent as $N \rightarrow \infty$, since conditional on $\boldsymbol{\theta}$ and $f_{t}$, the elements in the above sum are independently distributed. Also for a given estimate of $\mathbf{f}$, the optimization problem defined by (9) will yield a consistent estimate of $\boldsymbol{\theta}$ as $N$ and $T \rightarrow \infty$. Iterating between the solutions of the two optimization problems will deliver consistent estimates of $\boldsymbol{\theta}$ and $f_{1}, f_{2}, \ldots, f_{T}$, even though the number of incidental parameters, $f_{t}, t=1,2, \ldots, T$, is rising without bounds as $T \rightarrow \infty$. This is analogous to the problem of estimating time and individual fixed effects in standard linear panel data models. Individual fixed effects can be consistently estimated from the time dimension and time effects from the cross section dimension.

\subsection{Some monte carlo simulations}

In order to evaluate the performance of the two alternative estimation procedures (that is, the iterative procedure based on the cross-sectional estimates of $f_{t}$ and the Full Maximum Likelihood estimation of the model), we carried out a limited number of Monte Carlo

simulations. We generated the log price series according to the baseline model, (6), by setting $c=0.15, \sigma_{\varepsilon}=0.05, \sigma_{c}=0.01$ and simulating the common factors as the first order autoregressive process

$$
f_{t}=\rho_{0}+\rho_{1} f_{t-1}+\omega_{t}, \omega_{t} \backsim \text { i.i.d.N }\left(0, \sigma_{\omega}^{2}\right),
$$


with $\rho_{0}=0.05, \rho_{1}=0.90$, and $\sigma_{\omega}=0.10$. In Table 1 , we report the average (across $R$ replications ${ }^{10}$ ) of the point estimates of $c, \sigma_{\varepsilon}, \sigma_{c}$ and $\sigma_{v}$ and their average standard errors in different setups. Concerning the estimation of $f_{t}$, we compute the RMSE with respect to the true $f_{t}$ and compare the standard deviation of the true $f_{t}$ with that of the estimated $f_{t}$. In our reference case, the sample size is set at $N=50, T=50$.

\begin{tabular}{|c|c|c|c|c|c|c|c|c|}
\hline & & $c$ & $\sigma_{\varepsilon}$ & $\sigma_{c}$ & $\sigma_{v}$ & $R M S E\left(\tilde{f}_{t}\right)$ & $\frac{R M S E\left(\widetilde{f}_{t}\right)}{R M S E\left(f_{t}\right)}$ & $\mathrm{R}$ \\
\hline \multicolumn{9}{|c|}{ Average frequency of price changes $\sim 0.27$} \\
\hline With random effects & True value & 0.15 & 0.05 & 0.01 & 0.025 & & & \\
\hline \multirow[t]{2}{*}{$\mathrm{N}=50, \mathrm{~T}=50$, full $\mathrm{ML}$} & $\mathrm{ML}()$. & 0.150 & 0.049 & 0.011 & 0.027 & 0.00020 & 1.0011 & 500 \\
\hline & $\operatorname{std}()$. & 0.0014 & 0.0011 & 0.0013 & 0.0030 & & & \\
\hline No random effects & True value & 0.15 & 0.05 & 0.01 & 0 & & & \\
\hline \multirow[t]{2}{*}{$\mathrm{N}=50, \mathrm{~T}=50$, full $\mathrm{ML}$} & $\mathrm{ML}()$. & 0.150 & 0.049 & 0.007 & & 0.00014 & 1.0018 & 500 \\
\hline & $\operatorname{std}()$. & 0.0014 & 0.0011 & 0.0013 & & & & \\
\hline \multirow[t]{2}{*}{$\mathrm{N}=25, \mathrm{~T}=50$, full $\mathrm{ML}$} & $\mathrm{ML}()$. & 0.150 & 0.048 & 0.006 & & 0.00029 & 1.0051 & 500 \\
\hline & $\operatorname{std}()$. & 0.0019 & 0.0015 & 0.0018 & & & & \\
\hline \multirow[t]{2}{*}{$\mathrm{N}=50, \mathrm{~T}=25$, full $\mathrm{ML}$} & $\mathrm{ML}()$. & 0.150 & 0.049 & 0.003 & & 0.00014 & 1.0022 & 500 \\
\hline & $\operatorname{std}()$. & 0.0019 & 0.0015 & 0.0018 & & & & \\
\hline \multirow[t]{2}{*}{$\mathrm{N}=50, \mathrm{~T}=25$, iterative $\mathrm{ML}$} & $\mathrm{ML}()$. & 0.148 & 0.051 & 0.006 & & 0.00017 & 0.9907 & 500 \\
\hline & $\operatorname{std}()$. & 0.0019 & 0.0016 & 0.0017 & & & & \\
\hline \multicolumn{9}{|c|}{ Average frequency of price changes $\sim 0.12$} \\
\hline With random effects & true value & 0.300 & 0.050 & 0.100 & 0.025 & & & \\
\hline \multirow[t]{2}{*}{$\mathrm{N}=50, \mathrm{~T}=50$, full $\mathrm{ML}$} & $\mathrm{ML}()$. & 0.302 & 0.047 & 0.103 & 0.029 & 0.0005 & 1.0042 & 500 \\
\hline & $\operatorname{std}()$. & 0.0070 & 0.0017 & 0.0055 & 0.0037 & & & \\
\hline With random effects & true value & 0.300 & 0.100 & 0.125 & 0.250 & & & \\
\hline \multirow[t]{2}{*}{$\mathrm{N}=100, \mathrm{~T}=100$, full $\mathrm{ML}$} & $\mathrm{ML}(\cdot)$ & 0.307 & 0.099 & 0.131 & 0.247 & 0.0055 & 1.1720 & 500 \\
\hline & $\operatorname{std}()$. & 0.0105 & 0.0026 & 0.0078 & 0.0242 & & & \\
\hline \multicolumn{9}{|c|}{$R$ is the number of replications, $M L($.$) is the average of the point estimates, std(.) is the average$} \\
\hline
\end{tabular}

\section{Table 1 - Monte Carlo Simulations}

Under both estimation procedures, initial values for the estimation of $f_{t}$ are set to $\bar{p}_{t}$. In the iterative procedure, a first set of estimates for the remaining parameters of the model, $\boldsymbol{\theta}$, are then obtained by maximum likelihood, which is in turn used to compute another estimate of the unobserved common components, and the procedure is iterated until convergence. The standard errors of the parameter estimates are computed from the second derivatives of the full log-likelihood function.

The estimation of the models with and without random effects by the Full Maximum Likelihood roughly leads to similar results The point estimates and precision of the es-

\footnotetext{
${ }^{10}$ Because the estimation procedure with random effects takes much more time, we ran most simulations without random effects, and the number of replications is limited to 500 .
} 
timators are of the same order of magnitude, although the estimation of $\sigma_{c}$ appears to improve in a model with random effects. Considering the model without random effects, the estimates of the parameters $c$ and $\sigma_{\varepsilon}$ obtained by Full ML are essentially unbiased. However, $\sigma_{c}$ appears slightly underestimated in the simulations without random effects, contrary to the case with random effects. The unobserved component, $f_{t}$, is also very precisely estimated, and its volatility is only $0.14 \%$ higher than that of the true $f_{t}$.

Unsurprisingly, the precision of the estimates increases with the total size of the sample $N \times T$, as suggested by a comparison of the standard errors of the coefficients $c$, $\sigma_{\varepsilon}$ and $\sigma_{c}$, in the three alternative sets of simulations without random effects. However, increasing $N$ and $T$ do not play a symmetrical role in improving the precision of the point estimates. For small values of $N$ there seems to be a downward bias in estimating $\sigma_{\varepsilon}$. Furthermore, the RMSE of $\widehat{f}_{t}$ is higher and its volatility relative to that of the true $f_{t}$ increases $^{11}$. Decreasing $T$ from 50 to 25 does not seem to have any significant impact on the estimates, except for $\sigma_{c}$ which is now more severely underestimated. It might be for only quite low values of $T$ that the impact of ignoring the initial observations in the likelihood function could be non negligible.

We also report a comparison of the full ML and iterative estimation procedures. The results suggest that the point estimates of the coefficients are very close, and that the iterative procedure delivers a smoother $f_{t}$ than the full ML. ${ }^{12}$ The full ML may produce slightly better results in the sense that, as compared to the iterative procedure, the difference between the point estimate of $c$ and its true value is smaller, the RMSE of the estimated $f_{t}$ as compared to the true $f_{t}$ is lower, and its volatility is closer to the true one. Finally, in practice, the iterative procedure is much more time consuming than the "Full Maximum Likelihood" method. Therefore, we chose to estimate our baseline pricing model using the Full Maximum Likelihood method. Indeed, given the above Monte-Carlo results and the large size (in both $N$ and $T$ ) of our samples, we know that the two methods will not differ in any significant way and that the estimates obtained with the Full ML will be consistent and have a good precision.

In the above exercises, the parameters chosen lead to a frequency of price changes of around $27 \%$. This is close to the frequency of price changes reported by Bils and

\footnotetext{
${ }^{11}$ When the number of trajectories is small, the unobserved component $f_{t}$ is poorly estimated, because the cross-sectional dimension is too small for the idiosyncratic shocks, $\varepsilon_{i t}$, to cancel out by aggregation. This results in excessive volatility in the estimated $f_{t}$. Consequently, in order for the model to be in line with the observed frequency of price changes, the volatility of the idiosyncratic shock has to diminish.

${ }^{12}$ Iterative estimations made on real data for a limited number of products also produce less or equally volative $f_{t}$ as compared to the full ML estimate of $f_{t}$. The estimates of the other parameters are similar in the two estimation procedures.
} 
Klenow (2004) or Klenow and Kryvstov (2006) for the US. For a better comparison with our results and data sets, we also carried out a set of experiments where the frequency of price changes was set to around $12 \%$, which is closer to the frequencies observed in Europe (Dhyne et al., 2006). For these experiments, $c$ is set equal to 0.30 (and $\sigma_{c}$ is also increased to 0.10). As expected, the precision of the estimates is reduced when less price changes are observed. This is particularly true for $c$ and $\sigma_{c}$, which appear only in the part of the model corresponding to the price change trigger condition. Deviations from the true values, although larger than for higher frequencies of price changes, remain limited. Finally, we also report simulations for parameter values and sample size that are closer to our estimates based on Belgian and French data. Compared to the preceding case, the size of the idiosyncratic shock, $\sigma_{\varepsilon}$, and random effects, $\sigma_{v}$, are increased, while that of the common shock, $\sigma_{\omega}$ is reduced to 0.025 . $N$ and $T$ are set to 100 . Results are reported in the last panel of Table 1. They are of the same order of magnitude. Differences with the true values are slightly reduced,except for $c$ and $\sigma_{c}$.In this setup where the idiosyncratic shock plays a dominant role, with a reduced volatility of the true $f_{t}, \widehat{f}_{t}$ is less precisely estimated and its volatility is larger as compared to the that of the true $f_{t}{ }^{13}$

\section{Estimation Results}

The estimates of our baseline model, (6), are based on individual consumer price quotes compiled by the Belgian and French statistical institutes for the computation of their consumer price indices. ${ }^{14}$ These data refer to monthly price series of individual products sold in a particular outlet. The period covered has been restricted to the intersection of the two databases, that is July 1994 - February 2003. See Appendix B for further details about the two data sets.

Since we want to estimate our model for narrowly defined products, price series have been grouped into 368 product categories for Belgium and 305 for France. However, as the estimation procedure is particularly time consuming, ${ }^{15}$ the estimation has only been conducted on a subset of randomly selected product categories, with price trajectories of at least 20 months. ${ }^{16}$ As a result we end up estimating our baseline model for 98 product

\footnotetext{
${ }^{13} \sigma_{\varepsilon}$ is now four times larger as $\sigma_{\omega}$ while in the preceding exercise, $\sigma_{\varepsilon}$ was one half of $\sigma_{\omega}$.

${ }^{14}$ Each of these two datasets contains more than 10 millions observations. They are described in detail in Aucremanne and Dhyne (2004) for Belgium and in Baudry et al. (2007) for France.

${ }^{15}$ The estimation of our model for a typical product category, using S.A.S. 8.02 on a 1.6 Ghz P4 computer takes between 3 to 5 days.

${ }^{16}$ We define a price trajectory as a continuous sequence of price reports referring to one particular product sold in store i. The prices we refer to are (logs of) prices per unit of product so that promotions
} 
categories in Belgium and for 93 categories in France. Extended versions of the model (that allow for gradual or asymmetric adjustment costs) are also estimated with Belgian data for some selected product categories.

As stated above, we have opted, for practical reasons, for the "Full Maximum Likelihood" estimator so that we have simultaneously estimated, for each product category, the unobserved common component, $f_{t}$, as well as the other parameters, namely, the average level of the adjustment cost, $c$, and its variability, $\sigma_{c}$, the magnitude of the idiosyncratic shocks, $\sigma_{\varepsilon}$, and the variability of firms specific desired mark-up, $\sigma_{v}$. Finally, as we lack information on local competition or other factors that might affect the (log) optimal price, the outlet specific regressors, $\mathbf{x}_{i t}$, included in the model only contain a dummy variable corresponding to the nature of the outlet: the dummy takes the value of 1 whenever the outlet is a supermarket and 0 otherwise.

The response of actual prices to changes in the common component of the "optimal" price clearly depends on the profile of this common component. Variations in this common component are likely to induce price changes, even though they are partly predictable. For instance, changes in conventional wages are a good example of such predictable changes that induce variations in the optimal prices which in turn, are likely to lead to changes in actual prices. Such wage increases are largely predictable ${ }^{17}$ and have a clear impact on prices (e.g. see Loupias, Heckel and Sevestre (2007) for a study of French industrial price movements and Stahl (2005) for a study on German industrial prices).

Obviously, unpredictable common shocks (such as the impact of the "mad cow disease" on the demand for beef, the variations in the price of raw materials, or bad weather conditions affecting the harvest of vegetal products) may also have an impact on the likelihood of a price change.

In order to help interpret the impact on price changes of the variations in $f_{t}$, we propose a decomposition of these variations into several components: a trend, an autoregressive component and a random component. More specifically, for each product category, the estimates $\widehat{f}_{1}, \widehat{f}_{2}, \ldots, \widehat{f}_{T}$ are used to fit an $A R(K)$ model $^{18}$

$$
\widehat{f_{t}}=\beta_{0}+\beta_{1} t+\sum_{k=1}^{K} \rho_{k} \widehat{f}_{t-k}+\omega_{t}, \quad \omega_{t} \backsim i . i . d . N\left(0, \sigma_{\omega}^{2}\right) .
$$

in quantities are also captured in our analysis.

${ }^{17}$ For instance, in France, changes in the minimum wage are decided by the government and are put into effect annually in July. In Belgium, conventional wage changes for the next two years are negotiated every two years.

${ }^{18}$ For each product category, $K$ is selected to eliminate any serial correlation in $\omega_{t}$, using AIC applied to autoregressions with the maximum value of $K$ set to 12 . 
To characterize the magnitude of common variations in the optimal price, $p_{i t}^{*}$, in the following subsections, we use two different measures : the unconditional standard deviation of $f_{t}, \sigma_{f}$ and the standard error of shocks to the common factors, $\sigma_{\omega}$. The tables also provide some basic statistics such as the sum of the autoregressive coefficients, $\bar{\rho}=\sum_{k=1}^{K} \rho_{k}$. and the autocorrelation coefficients of orders $1,2,3,4,6$ and 12 of the estimated $f_{t}$ 's.

Table 2 below presents a summary of the estimates by broad product categories. ${ }^{19}$

\subsection{Assessing intrinsic rigidities}

Overall, the estimates obtained for Belgium and France lead to similar conclusions. The average level of the adjustment cost is estimated to represent one third of the price level (36\% in Belgium and 31\% in France). These estimates are comparable to the relative magnitude of the estimated menu costs reported in Levy et al. (1997) for the US. Indeed, Levy et al. (1997), using a data set on prices, sales and costs in 5 large multi-store chains, report estimates of menu costs in the US retail grocery trade, ranging from $\$ 0.46$ to $\$ 1.33$ per price change; which represent $27 \%$ to $40 \%$ of the average price level.

Since numerous studies point to a remarkable ranking of the frequency of price changes according to the product category (e.g. see Bils and Klenow, 2004, for the US and Dhyne et al., 2006, for the euro area), it is also worth considering the average adjustment costs by product categories. These are given in the first column of Table $2 .{ }^{20}$ The most striking conclusion from the simple comparison of the price change frequencies with the estimated adjustment costs is that indeed, the incidences of less frequent price changes are often associated with larger estimates of the adjustments costs.

The relatively high frequency of price changes observed for energy and especially oil products can partly be explained by relatively low adjustment costs: the mean adjustment cost estimate, $\hat{c}$, for oil energy products is on average in the range $0.012-0.014$ for Belgium and $0.004-0.007$ for France, compared to sample averages for the product categories as a whole. of 0.365 for Belgium and 0.328 for France. Similarly, numerous

\footnotetext{
${ }^{19}$ Tables A and B in the appendix first present detailed results for the estimated structural parameters and the time-series representation of the estimated common component. These tables also include some basic statistics that characterize the price setting behavior of each product category (frequency of price changes, average absolute size of price changes, share of price increases) and indicators of the ability of the model to replicate these characteristics. In the case of Belgium, the correlations between $\widehat{f}_{t}$ and $\overline{p_{t}}$ and between $\widehat{f}_{t}$ and the log of the product category price index, $\ln \left(I P_{t}\right)$, are also provided. Tables $\mathrm{C}$ and $\mathrm{D}$ in Appendix $\mathrm{C}$ provide further statistics associated with the estimated common component.

${ }^{20}$ The figures in this table are unweighted. They have been computed after the exclusion of 8 products for Belgium and 2 products for France for which the model appeared to fit particularly badly to the data. See Section 4.4 below.
} 
price changes of perishable food products are associated with low mean adjustment costs. Our estimates for these products are very close to the numbers reported in Ratfai (2006) for meat products in Hungary. At the opposite, manufactured goods and services exhibit higher mean adjustment costs that explain, at least partly, the often underlined stronger stickiness of their prices.

\begin{tabular}{|c|c|c|c|c|c|c|c|c|c|c|}
\hline Product type & $\widehat{c}$ & $\widehat{\sigma_{\varepsilon}}$ & $\widehat{\sigma_{c}}$ & $\widehat{\sigma_{u}}$ & $\widehat{\sigma_{f}}$ & $\widehat{\sigma_{\omega}}$ & $\widehat{\bar{\rho}}$ & req & $\Delta p$ & \%up \\
\hline \multicolumn{11}{|c|}{ Energy (BE - 3 product categories ; FR - 2 product category) } \\
\hline & 01 & 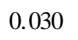 & 006 & 0.05 & 0.176 & 0.038 & 866 & 31 & 0.043 & \\
\hline & 0.005 & 0.020 & 004 & & 0.112 & & & & .023 & \\
\hline \multicolumn{11}{|c|}{ Perishable food (BE - 24 product categories ; FR - 13 product categories) } \\
\hline & רา & 0 & 0.143 & 0.1. & 0.073 & 30 & 4 & 30 & 0.128 & 0.648 \\
\hline & 0.170 & . & 0.100 & 0.267 & 0.067 & & 0.901 & & 107 & \\
\hline \multicolumn{11}{|c|}{ Non perishable food (BE - 12 product categories ; FR - 11 product categories) } \\
\hline & 0.309 & 0.080 & 0.173 & 0.202 & 0.055 & & 0.802 & & 0.104 & 0.627 \\
\hline & 0.190 & & 0.125 & 0.2 & 0.064 & & 6 & & .059 & \\
\hline \multicolumn{11}{|c|}{ Non durable goods (BE - 15 product categories ; FR - 31 product categories) } \\
\hline & 0375 & 0.079 & 0178 & 0233 & 0.064 & 0.013 & 0.852 & & 0.089 & 36 \\
\hline Hivelo & $0.4 x$ & 0.100 & 0.219 & 0.433 & 0.074 & & 0.283 & & 0.180 & \\
\hline \multicolumn{11}{|c|}{ Durable goods (BE - 17 product categories ; FR - 13 product categories) } \\
\hline & 0547 & 0070 & 0264 & 0228 & 0057 & 0014 & 0.739 & & 0.076 & 0.613 \\
\hline e & 0. & 0. & 0. & 0.4 & 0.077 & 0 & 5 & & 0.083 & 0.487 \\
\hline \multicolumn{11}{|c|}{ Services (BE - 19 product categories ; FR - 21 product categories) } \\
\hline & 0. & & 8 & 0 & 0 . & & 3 & & 0.062 & 0.050 \\
\hline e & 0.370 & 0 . & 0.111 & 0.2 & 0.066 & 3 & 12 & & 0.054 & $7+7$ \\
\hline \multicolumn{11}{|c|}{ Full basket (BE - 90 product category - FR - 91 product categories) } \\
\hline & 0.365 & 0 & 0.178 & 0.187 & 0.077 & 0.019 & 0.754 & 0.146 & 0.092 & 0.681 \\
\hline Average - France & 0.328 & 0.087 & 0.176 & 0.341 & 0.071 & 0.028 & 0.593 & 0.157 & 0.109 & 0.595 \\
\hline
\end{tabular}

TABle 2 - Estimation RESUlts By BROAd PROduCt CATEgories

Another striking result is that, for all product types, except for oil products, the average adjustment costs are larger than the average size of price changes. Initially, this may be considered as a rather puzzling result. However, it can be rationalized noting the stochastic nature of the adjustment cost variable, $c_{i t}$. Indeed, since the distribution of $c_{i t}$ is symmetric around its mean, $c$, the likelihood that a price change occurs is larger the lower the realized adjustment cost i.e., for negative values of $\left(c_{i t}-c\right)$, as compared to the positive case where $c_{i t}-c$ is positive. Therefore, small price changes are more likely than large ones, which lowers the average size of price changes. ${ }^{21}$ This may explain why, despite significant average adjustment costs, a large number of small price changes are observed.

\footnotetext{
${ }^{21}$ We thank H. LeBihan for this insight. This is easy to check with a simulation where, setting $\sigma_{c}^{2}$ equal to 0 leads to the expected result: the average size of price changes is larger than $c$.
} 
Although we observe globally the expected negative correlation between the frequency of price changes and the estimated mean adjustment cost, the observed differences in the frequency of price changes across products are not fully explained by those in the estimated $c$. This can be illustrated by the following two examples. First, the monthly frequency of price changes associated with beef sirloin (14.9\%) in the Belgian data set represents only a fourth of the frequency of price changes of Kiwis (54,2\%). However, the adjustment costs of these two products are of the same order of magnitude ( $\hat{c}$ equal to 0.166 for sirloin compared to 0.141 for Kiwis). Therefore, differences in the frequency of price changes must originate in differences in the size of the common and/or idiosyncratic

shocks. A second interesting example relates to men's suit and sugar in France. While the observed frequencies of price changes of these two products are quite similar $(16.7 \%$ and $17.0 \%$, respectively), their estimated adjustment costs differ markedly as their respective estimates are 0.33 for the former product and only 0.13 for the latter.

\subsection{Assessing extrinsic rigidities}

Our estimates show that extrinsic rigidity (the magnitude of shocks, both common and idiosyncratic, to the optimal price) does play an important role in explaining the frequency of price changes. This result can be readily illustrated using the two examples discussed above. In the case of men suits and sugar in France, we observe strong differences in the profile and magnitude of the shocks affecting the optimal prices of these two product categories. First, the overall variability of the common component $f_{t}$ (as measured by $\sigma_{f}$ ) appears to be larger for men suits than for sugar. Interestingly, the profiles over time of these two common components differ markedly. Indeed, the autocorrelation profile of the estimated $f_{t}$ 's for men suits exhibit a high degree of autocorrelation at lag orders 6 and 12, suggesting strong seasonal effects in prices. A reasonable interpretation of this result lies in the prevalence of promotion sales that strongly affect prices of clothing. This is a situation where the profile of the common component contributes to the understanding of the observed frequency of price changes. Second, idiosyncratic shocks affecting men suit optimal prices are of a much larger magnitude than those affecting sugar prices, explaining why men suit prices vary as much as sugar prices over time, despite its higher adjustment costs. The importance of the idiosyncratic component may reflect the outlet specific "marketing policy" regarding sales. Consider now Kiwis and sirloin in Belgium. While the frequencies of their price changes are quite different, these two products exhibit very similar mean adjustment cost estimates Then, this difference must stem from differences in the magnitude of idiosyncratic shocks affecting the price of 
these two products ( $\sigma_{\varepsilon}$ equals 0.058 for sirloin compared to 0.203 for Kiwis) and/or from differences in the the unconditional variability of the common factors associated with these two product categories ( $\sigma_{f}$ equals 0.020 for sirloin compared to 0.172 for Kiwis).

Overall, our estimates clearly show the relative importance of idiosyncratic shocks for our understanding of the price change frequencies. With a very few exceptions (mainly energy products), the magnitude of idiosyncratic shocks is generally larger than the (unconditional) variability of the common component $\sigma_{f}$. Over the entire range of products, the ratio of $\widehat{\sigma}_{\varepsilon}$ to $\widehat{\sigma}_{f}$ takes values above one for $60 \%$ of the product categories in Belgium and in $70 \%$ of cases in France. ${ }^{22}$ Considering $\widehat{\sigma}_{\omega}$ instead of the unconditional standard deviation of the $f_{t}$ 's obviously yields much larger values for this ratio. This result is in line with the conclusion of Golosov and Lucas (2003) who state that price trajectories at the micro level are largely affected by idiosyncratic shocks.

\subsection{Intrinsic and extrinsic rigidities and the frequency of price changes}

Our main findings so far, can be summarized as follows: the relatively high frequency of price changes observed for energy, and especially oil products, can be explained by the low values of the mean adjustment costs parameter, but also by a significant variability of $\widehat{f}_{t}$ for this product category. Indeed, for Belgium, the unconditional standard deviation of $\widehat{f}_{t}, \widehat{\sigma}_{f}$, lies between 0.114 and 0.263 for the three energy products considered (resp. between 0.091 and 0.133 in France) while it averages to only 0.077 for the set of products as a whole (resp. 0.071 in France). Both in Belgium and France, the consumer prices of the energy products is thus largely determined by the common movements in marginal costs (which are highly correlated with the price of oil products on the international markets as illustrated in Figure 2). The contribution of idiosyncratic shocks and the dispersion of firm specific mark-ups is of second order importance, compared to what is observed in the other product categories. ${ }^{23}$

\footnotetext{
${ }^{22}$ The average value of this ratio over the 88 product categories considered in the Belgian sample is 1.74 and it is 1.59 in the French sample.

${ }^{23}$ In the case of Belgium, this might be due to the fact that oil prices at the gas station are regulated (there is an agreement between the government and oil companies to set up the maximum prices of oil product).
} 


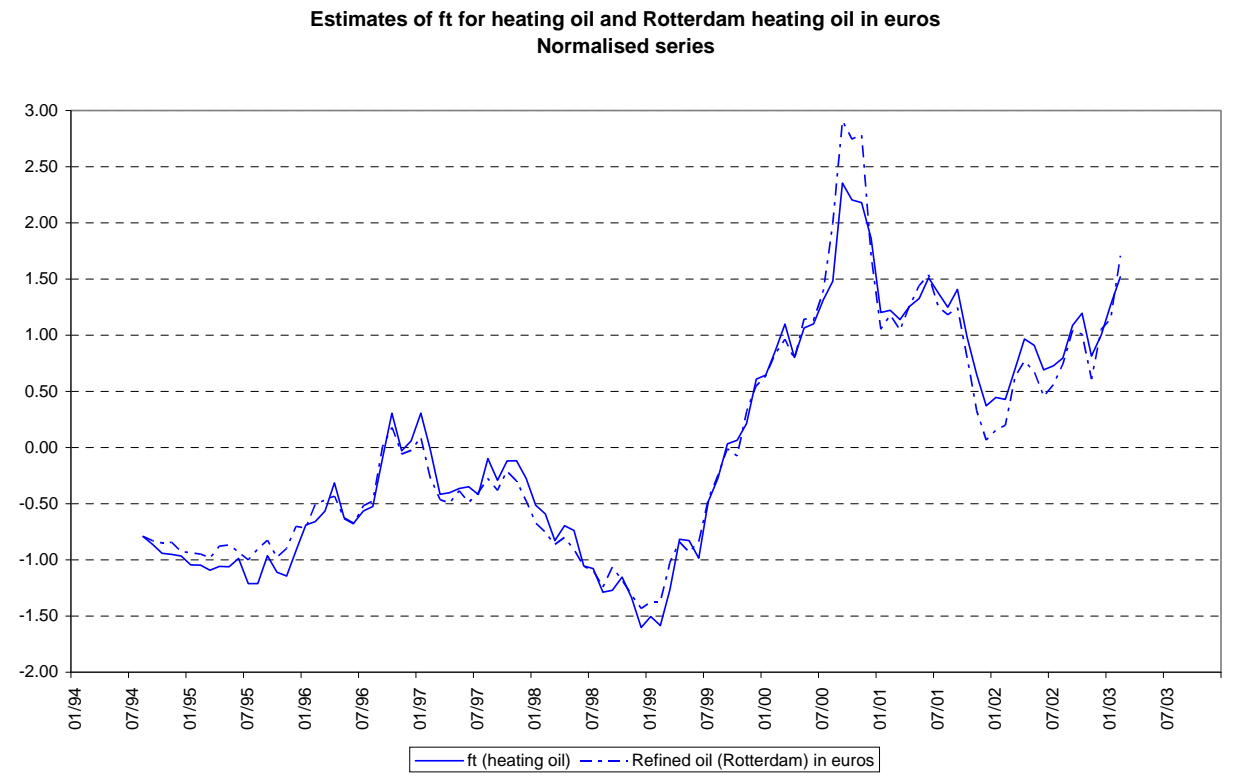

Figure 2 - Evolution of COMmon COMponent $\widehat{f}_{t}$ For HeAting oil and of REFINED OIL ON ROTTERDAM MARKET

The perishable food product categories, which rank second in terms of the frequency of price changes both in Belgium and in France, are characterized by medium sized adjustment costs ( $c$ is estimated to be 0.274 in Belgium, 0.196 in France) but these product categories are affected by relatively important common and idiosyncratic shocks. In other words, intrinsic rigidities appear here again to be the main reason for the observed "mild" stickiness of these product prices. It is worth noticing that for France, the slightly lower frequency of price changes observed for non perishable food products seems to be only the consequence of lower idiosyncratic shocks, all the other parameters being quite close to those obtained for non perishable food products. This is another clear illustration of the role of extrinsic rigidity. At the opposite side of the spectrum, the most sticky components of the CPI in Belgium (services and durable goods) and in France (services) are characterized by higher adjustment costs but also, in Belgium, by smaller idiosyncratic and common shocks. Some services in France are also characterized by smaller shocks but there seems to be a significant heterogeneity in this respect. Finally, the frequency of price changes for the remaining categories (non perishable food and non durable industrial goods in Belgium; durable and non durable goods in France) is driven by both slightly larger than average adjustment costs and a lower variability of the idiosyncratic and common components of the optimal price. Then, the relative stickiness of these prices are due to both intrinsic and extrinsic rigidities, where the latter seems to be more "concentrated" in the common component of the price, while idiosyncratic shocks appear 
to be an important factor of price variability in those sectors.

In conclusion, the frequency of price changes seems, unsurprisingly, to be closely related to the ratio of the variability of the optimal price over time, as measured by $\sqrt{\sigma_{\varepsilon}^{2}+\sigma_{f}^{2}}$, to the mean adjustment cost parameter $c$. Indeed, the simple correlation between the frequency of price changes and this ratio is 0.708 for Belgium, and 0.818 for France.

For a deeper understanding of the link between the frequency of price changes and the structural parameters of the model, we have estimated a simple equation relating the frequency of price changes to the estimated adjustment costs parameter, $\hat{c}$, the volatility of the idiosyncratic and the common shocks, $\hat{\sigma}_{\varepsilon}$ and $\hat{\sigma}_{\omega}$, respectively. Two groups of regressions are run. First, three linear regressions explaining the observed frequency of price changes $\left(\right.$ freq $\left._{i}\right)$ are estimated by OLS. A second set of regressions with the dependent variable defined as the logit transformation of the frequencies (i.e. $\ln \left[f r e q_{i} /\left(1-\right.\right.$ freq $\left.\left._{i}\right)\right]$ ) is also estimated by the quasi maximum likelihood (QML) estimation procedure proposed by Papke and Wooldridge (1996). These regressions are run on the sample of product categories for which the quality of the fit was good (see below), i.e., 90 product categories for Belgium and 91 product categories for France. Table 3 reports the results (with standard errors in brackets). The QML and OLS provide qualitatively similar results, although the QML procedure provides a better fit, ${ }^{24}$ which favours a non-linear relation between the structural parameters and the frequency of price changes.

\begin{tabular}{|c|c|c|c|c|c|c|}
\hline & \multicolumn{3}{|c|}{ OLS } & \multicolumn{3}{|c|}{ QML } \\
\hline & (1) & (2) & (3) & (4) & (5) & (6) \\
\hline const & $\begin{array}{l}0.252 \\
(0.019)\end{array}$ & $\begin{array}{l}0.146 \\
(0.011)\end{array}$ & $\begin{array}{l}0.154 \\
(0.012)\end{array}$ & $\begin{array}{c}-1.044 \\
(0.240)\end{array}$ & $\begin{array}{c}-1.732 \\
(0.112)\end{array}$ & $\begin{array}{c}-1.673 \\
(0.104)\end{array}$ \\
\hline France & $\begin{array}{c}-0.050 \\
(0.015)\end{array}$ & $\begin{array}{c}-0.012 \\
(0.008)\end{array}$ & $\begin{array}{c}-0.014 \\
(0.008)\end{array}$ & $\begin{array}{l}0.054 \\
(0.106)\end{array}$ & $\begin{array}{l}0.165 \\
(0.057)\end{array}$ & $\begin{array}{l}0.152 \\
(0.053)\end{array}$ \\
\hline$\widehat{c}$ & $\begin{array}{c}-0.715 \\
(0.043)\end{array}$ & $\begin{array}{c}-0.409 \\
(0.026)\end{array}$ & $\begin{array}{c}-0.433 \\
(0.029)\end{array}$ & $\begin{array}{c}-6.169 \\
(0.476)\end{array}$ & $\begin{array}{c}-4.171 \\
(0.210)\end{array}$ & $\begin{array}{c}-4.607 \\
(0.287)\end{array}$ \\
\hline$\widehat{\sigma_{\varepsilon}}$ & $\begin{array}{l}1.643 \\
(0.184)\end{array}$ & $\begin{array}{l}1.121 \\
(0.098)\end{array}$ & $\begin{array}{l}1.223 \\
(0.119)\end{array}$ & $\begin{array}{c}10.000 \\
(1.592)\end{array}$ & $\begin{array}{l}9.205 \\
(0.898)\end{array}$ & $\begin{array}{c}11.579 \\
(1.167)\end{array}$ \\
\hline$\widehat{\sigma_{\omega}}$ & $\begin{array}{l}1.603 \\
(0.344)\end{array}$ & $\begin{array}{l}0.493 \\
(0.186)\end{array}$ & $\begin{array}{l}0.441 \\
(0.202)\end{array}$ & $\begin{array}{c}10.980 \\
(2.590)\end{array}$ & $\begin{array}{l}4.929 \\
(2.223)\end{array}$ & $\begin{array}{l}3.197 \\
(2.331)\end{array}$ \\
\hline$\frac{\sqrt{\widehat{\sigma_{\varepsilon}^{2}} \widehat{\sigma_{\omega}^{2}}}}{\widehat{c}}$ & - & $\begin{array}{l}0.101 \\
(0.004)\end{array}$ & - & - & $\begin{array}{l}0.416 \\
(0.048)\end{array}$ & - \\
\hline$\frac{\widehat{\sigma_{\varepsilon}}}{\widehat{c}}$ & - & - & $\begin{array}{l}0.069 \\
(0.014)\end{array}$ & - & - & $\begin{array}{l}0.030 \\
(0.124)\end{array}$ \\
\hline$\frac{\widehat{\sigma_{\omega}}}{\widehat{c}}$ & - & - & $\begin{array}{l}0.075 \\
(0.017) \\
\end{array}$ & - & - & $\begin{array}{l}0.639 \\
(0.176) \\
\end{array}$ \\
\hline$R^{2}$ & 0.649 & 0.906 & 0.898 & 0.800 & 0.940 & 0.955 \\
\hline
\end{tabular}

Table 3 - Relation Between frequency of Price Changes and Structural PARAMETERS

\footnotetext{
${ }^{24}$ This is particularly true of the specification that excludes the $\hat{c} / \hat{\sigma}_{\varepsilon}$.
} 
These regressions confirm that the frequency of price changes is strongly influenced by the size of the shocks, as estimated by $\hat{\sigma}_{\varepsilon}$ and $\hat{\sigma}_{\omega}$, relative to the adjustment costs parameter, $\hat{c}$. If larger adjustment costs tend to significantly reduce the frequency of price changes, this effect can be partly offset by larger shocks to the marginal costs/desired mark-up. Introducing the relative importance of idiosyncratic shocks and common shocks separately also indicates that it is mostly the relative size of the common shock that determines the frequency of price changes. ${ }^{25}$

\subsection{Evaluating the fit of the model}

In order to assess how well the model fits the data, we compare the realized frequency and average size of price changes with those obtained by simulating the model. More precisely, for each product, we simulate an unbalanced panel of price trajectories starting with $p_{i 0}$, the observed initial value of each price trajectory $i$, using the estimated values of $c, f_{t}$ and randomly generated $\varepsilon_{i t}$ 's and $c_{i t}$ 's with respective standard-errors $\widehat{\sigma}_{\varepsilon}, \widehat{\sigma}_{c}$ as well as an estimate of $u_{i}$. Indeed, as the true initial value $p_{i 0}$ is used as starting value of the $i^{t h}$ price trajectory, the true $u_{i}$ should be used to simulate the subsequent price observation of that trajectory. Since $u_{i}$ is unknown, the simulation exercise is based on an estimated $\widehat{u}_{i}$ which is computed by re-estimating our baseline model with trajectory specific fixed effects, keeping the other parameters of the model $\left(\widehat{c}, \widehat{\sigma}_{\varepsilon}, \widehat{\sigma}_{c}, \widehat{f}_{t}\right)$ as given. The time dimension of the simulated trajectory $i$ is set to coincide with the length of the associated realized price trajectory. The number of price trajectories in the simulated panels is given by the number of trajectories in the observed panels. The experiment is repeated 1000 times for each trajectory.

For each product category and their simulated counterparts, the frequency of price changes, the average (absolute) size of price changes and the share of price increases are computed. Scatter plots of these statistics for the 98 product categories in the Belgian CPI are presented in Figure 3. Similar graphs would be obtained using the French estimates. Figures 3a shows that, except for a small number of products (8 out of 98), the observed frequencies of price changes match the simulated ones quite well. The same is also true for France where except for 2 product categories (out of 93), the actual and simulated frequencies match very closely. ${ }^{26}$ The few cases where the simulations do not match the

\footnotetext{
${ }^{25}$ Using the standard deviation of $\hat{f}_{t}$ instead of $\hat{\sigma}_{\omega}$ does not induce any change in the conclusions.

${ }^{26}$ The 10 product categories for which our estimated parameters do not allow to replicate the characteristics of the observed price trajectories are, for Belgium, "Dining room oak furniture", "Cup and saucer", "Parking spot in a garage", "Fabric for dress", "Wallet","Small anorak (9 month)"; "Men T Shirt" and "Hair spray $400 \mathrm{ml}$ ", and for France, "classic lunch in a restaurant" and "pasta". These
} 
realizations are confined to product categories with relatively rigid prices. In the case of these products our simulations lead to an overestimation of the frequency of price changes, and to an underestimation of the average size of the price change. Moreover, these product categories are characterized by a very high degree of heterogeneity in the price dynamics, which translates into a large degree of heterogeneity in the adjustment costs parameter, $c_{i t}$. When $\sigma_{c}$ is very large as compared to $c$, our model could, in principle generate negative menu costs. This leads to a failure of the simulated samples to reproduce the data characteristics. ${ }^{27}$

a. Frequency of price changes

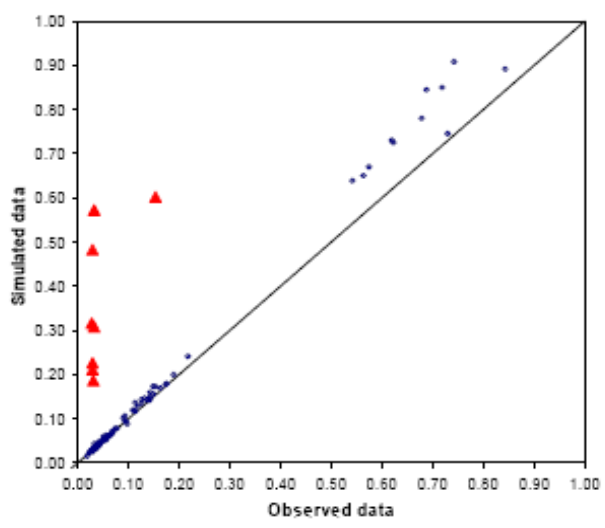

c. Average $\left|\Delta p_{\text {it }}\right| \neq 0$

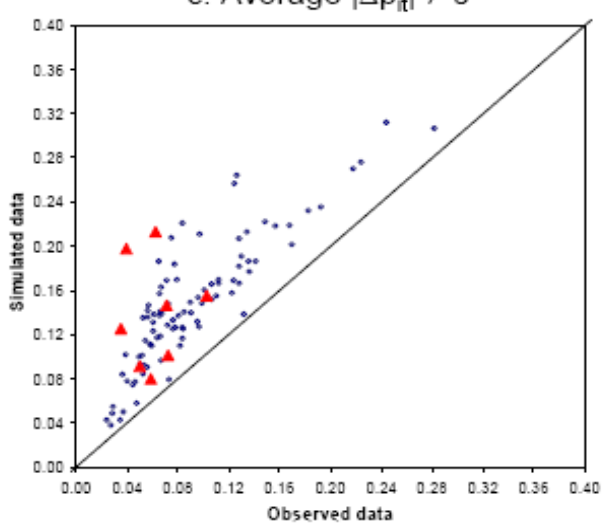

b. Average $\Delta \mathrm{p}_{\text {it }} \neq 0$

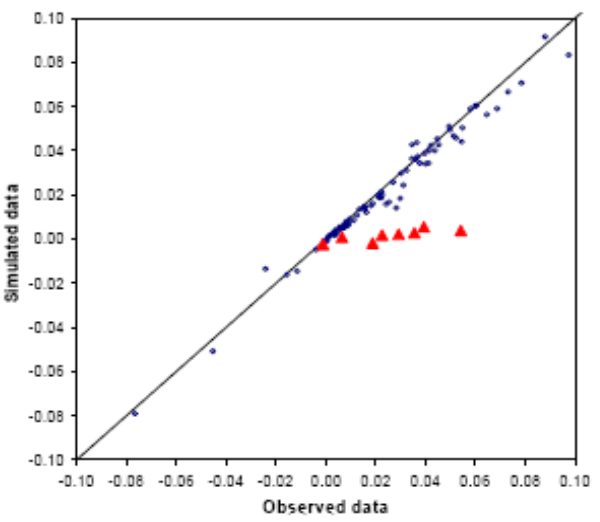

d. Share of price increases

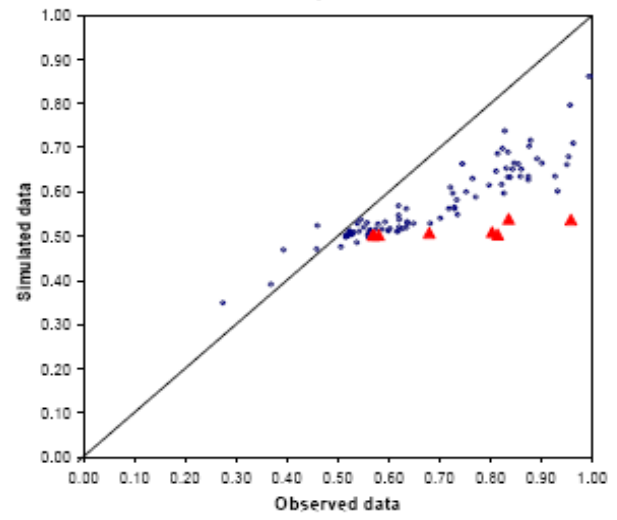

\section{Figure 3 - Characteristics of observed ANd Simulated trajeCtories}

The quality of the fit appears to be less satisfactory regarding the two other characteristics of price changes: their average magnitude and the proportion of price increases, both for Belgium and France. While the proportion of price increases seems to be underestimated in most cases, the magnitude of price changes is overestimated. Since the products were not considered in the OLS/QML estimation presented in section 4.3

${ }^{27}$ The detailed results are provided in appendix $\mathrm{C}$. 
estimated common component appears to fit quite well the specific price indices of each category (see the correlation between $f_{t}$ and these indices in table $\mathrm{A}$, appendix $\mathrm{C}$ ), it seems reasonable to conclude that the cause of this problem lies, at least partly, in the idiosyncratic shocks affecting the optimal prices. Indeed, this outcome may result from an overestimation of the size of the idiosyncratic shock and/or from the assumption of pure randomness of the $c_{i t}$ 's around their mean. Given this randomness, we may face a number of cases where an observed price increase (resp. a decrease) corresponds, in our model to a situation which would normally induce no price changes (because $c_{i t}$ is high and positive), thus implicitly requiring a large positive (resp. negative) shock to make the observed price change likely. Accounting for differences in adjustment costs that are not purely random (such as differences across types of outlets, seasonal variations, etc.) might then be a way to improve our estimates. Regarding the underestimation of the proportion of price increases, one may wonder whether the assumption of no serial correlation in the $\varepsilon_{i t}$ and the symmetric distribution of the $c_{i t}$ 's may explain the underestimation of the proportion of price increases. Indeed, one can observe that for the few products exhibiting a low proportion of price increases, this proportion is overestimated. It might be the case that the symmetry assumed here leads to a bias of the frequency of price increases towards 0.5. A first exploration of this asymmetry issue is provided below.

\subsection{Some Extensions of the Empirical Results}

\subsubsection{Gradual adjustments}

As stated in Section 2, several factors, such as the structure of local competition across outlets, the degree of uncertainty in the identification of the shocks to the marginal cost, consumers' inattention, or costly information can motivate a partial adjustment to shocks. However, in order to observe such gradual movements in prices, price changes should be made on a relatively frequent basis. If a firm adjusts its price only once a year, a gradual change might not be sensible. Therefore, a price setting model with partial adjustment should only be estimated for product categories with relatively frequent price changes. For these product categories, the partial adjustment parameter $\lambda$ introduces an additional source of intrinsic rigidity.

In the following table, we present the estimation results associated with a set of three product categories characterized by relatively frequent price changes (heating oil, oranges and roses). We also present the estimation results for two product categories that in comparison are characterized by less frequent price changes (namely central heating 
repair tariff and hourly rate of a painter).

\begin{tabular}{lccccc}
\hline Parameters & Heating oil & Oranges & Roses & Central heating & Painter \\
\hline$\widehat{c}$ & $0.025^{* *}$ & $0.075^{* *}$ & $0.076^{* *}$ & $0.396^{* *}$ & $0.144^{* *}$ \\
$\widehat{\sigma_{\varepsilon}}$ & $0.052^{* *}$ & $0.247^{* *}$ & $0.291^{* *}$ & $0.074^{* *}$ & $0.220^{* *}$ \\
$\widehat{\sigma_{c}}$ & $0.010^{* *}$ & $0.056^{* *}$ & $0.033^{* *}$ & $0.190^{* *}$ & $0.066^{* *}$ \\
$\widehat{\sigma_{v}}$ & $0.044^{* *}$ & $0.109^{* *}$ & $0.247^{* *}$ & $0.151^{* *}$ & $0.221^{* *}$ \\
\hline$\widehat{\lambda}$ & $0.342^{* *}$ & $0.395^{* *}$ & $0.436^{* *}$ & $0.076^{* *}$ & $0.864^{* *}$ \\
\hline $\operatorname{Logl}$ & 14755.9 & -13921.2 & -6098.8 & -3114.5 & -2311.9 \\
$\widehat{\sigma_{\omega}}$ & 0.097 & 0.067 & 0.076 & 0.004 & 0.062 \\
\hline$\widehat{\rho}$ & 0.867 & 0.498 & 1.038 & 0.848 & 0.187 \\
\hline
\end{tabular}

Table 4 - estimation Results with gradual adjustment - Belgium $* *=$ significant at the $1 \%$ level $*=$ significant at the $5 \%$ level

The results are summarized in Table 4 . The estimates of $\lambda$, the parameter of the partial adjustment, is statistically significant for all five product lines considered, with values that seem eminently sensible for product categories characterized by very frequent price changes. Our estimates indicate that for this kind of products, there is a statistically significant evidence of gradualism in the price setting behavior of firms. This clearly indicates an additional source of extrinsic rigidity. The estimate of $\lambda$ for "central heating repair tariff" is much smaller, and is in accordance with our prior belief that when a firm adjusts its price rarely, it does it (almost) fully. However, we obtain a very high estimate of $\lambda$ for an "hourly rate of a plumber" which is difficult to explain from an economic point of view. This last result could be due to the fact that the estimation of a gradual adjustment price setting model on price trajectories that do not contain any price change might be quite problematic. We have conducted some simulations showing that the observation of flat price trajectories biases the estimation of the $\lambda$ parameter towards one, introducing a high volatility in the unobserved common component.

\subsubsection{Asymmetric adjustment costs}

As mentioned earlier, our estimates so far are based on the assumption of symmetric adjustment costs. As noted earlier this assumption does not rule out asymmetry in the observed direction of price changes. If the estimated common component, $\hat{f}_{t}$, is characterized by a positive (negative) trend, our price setting model will generate more price increases (decreases). This is consistent with the argument of Ball and Mankiw (1994).

However, in order to test whether relaxing this assumption could help in capturing the observed degree of asymmetry in the direction of price changes, we have estimated 
our baseline model introducing different average adjustment cost parameters for price increases $\left(c_{U}\right)$ and for price decreases $\left(c_{L}\right) .{ }^{28}$ This estimation has been conducted on product categories mainly exhibiting symmetric price changes (e.g. oranges and heating oil) and for product categories that largely show asymmetric price changes (e.g. special beer in a bar, dry cleaning of a shirt). The results are given in Table 5 .

\begin{tabular}{lccccccc}
\hline & Oranges & Special beer & Heating oil & Dry cleaning (shirt) & Biscuits & Sausage & Cheese (Edam) \\
$\widehat{\widehat{c_{u p}}}$ & $0.079^{* *}$ & $0.543^{* *}$ & $0.025^{* *}$ & $0.556^{* *}$ & $0.226^{* *}$ & $0.440^{* *}$ & $0.323^{* *}$ \\
$\widehat{c_{\text {down }}} \widehat{\bar{c}_{\text {up }}}$ & 0.000 & $-0.02^{*}$ & $0.001^{* *}$ & $-0.004^{* *}$ & 0.000 & $-0.001^{* *}$ & 0.000 \\
$\widehat{\sigma_{\varepsilon}}$ & $0.159^{* *}$ & $0.052^{* *}$ & $0.036^{* *}$ & $0.063^{* *}$ & $0.067^{* *}$ & $0.110^{* *}$ & $0.086^{* *}$ \\
$\widehat{\sigma_{c}}$ & $0.063^{* *}$ & $0.237^{* *}$ & $0.011^{* *}$ & $0.251^{* *}$ & $0.146^{* *}$ & $0.230^{* *}$ & $0.174^{* *}$ \\
$\widehat{\sigma_{u}}$ & $0.109^{* *}$ & $0.151^{* *}$ & $0.040^{* *}$ & $0.172^{* *}$ & $0.189^{* *}$ & $0.165^{* *}$ & $0.134^{* *}$ \\
$\widehat{\text { hyper }}$ & $-0.019^{* *}$ & 0.000 & - & - & $-0.036^{* *}$ & $-0.108^{* *}$ & -0.020 \\
\hline$l(\theta)$ & -27381.4 & -3076.4 & 13892.6 & -2651.650 & -19870.0 & -17460.127 & -12410.890 \\
\hline
\end{tabular}

Table 5 - Estimation Results with asymmetric menu costs - Belgium

$* *=$ significant at the $1 \%$ level $*=$ significant at the $5 \%$ level

The main conclusion emerging from these estimates is that adjustment costs associated with price decreases do not seem to differ much from the adjustment costs associated with price increases. Even if the difference between the two adjustment costs are statistically significant, the difference does not seem to be economically important. Although this conclusion is based on a limited number of cases, it supports the view that asymmetric price changes are more likely to result from a trend in $f_{t}$ rather than from asymmetric adjustment costs. However, further research is needed to check whether other sources of asymmetry may matter or not.

\section{Conclusion}

Modern macroeconomics has emphasized the role of price rigidity in the impact of monetary policy on economic activity and inflation dynamics. The slope of the New Keynesian Phillips curve typically depends on intrinsic price rigidity. Most previous empirical literature approximated these intrinsic rigidities by the frequency of price changes. However, in the case of state dependent rules, the frequency of price changes does not only depend on the size of the adjustment costs (intrinsic rigidity), but is also affected by the distribution of shocks that affect outlets (extrinsic rigidity).

\footnotetext{
${ }^{28}$ It is also possible to introduce asymmetry in the variability of the adjustment costs, but we do not pursue this here.
} 
Following this new strand in theoretical models (see Dotsey, King and Wolman, 1999, and Gertler and Leahy, 2006), we specify a state-dependent (s,S) type model where outlets do not necessarily instantaneously adjust their prices in response to changes in their environment. Since the optimal price targeted by outlets is unobserved, we decompose it into three components: first, a component that is shared across all outlets selling a given fairly homogeneous product. From an economic point of view, this component reflects the average marginal cost augmented with the average outlet-specific desired mark-up associated with this particular product. We model this as a common factor. The second component of the unobserved optimal price is an outlet specific effect, which accounts for product differentiation, local competition conditions, etc.. The third component is an idiosyncratic term, reflecting shocks that may affect the outlet specific optimal price (possibly due to outlet specific demand shocks or unexpected changes in costs, etc.).

This set up involves modeling of the price changes as a non-linear dynamic panel model with unobserved common effects, which allows us to decompose price stickiness into intrinsic and extrinsic components, associated with the variability of the various components of the (unobserved) optimal price. Making use of two large data sets composed of consumer price records used to compute the CPI in Belgium and France, we estimate these different components for a large number of homogenous product categories. Our results show that the now well-documented differences across products in the frequency of price changes do not strictly correspond to differences in terms of adjustment costs; i.e. intrinsic rigidity does not suffice to explain the frequency of price changes. What seems to drive the frequency of price changes is the relative importance of adjustment costs to the size of the shocks, common and/or idiosyncratic.

The high frequency of price changes in the most flexible components of the CPI (energy products and perishable foods) is mainly related to large idiosyncratic and/or common shocks, and not necessarily to small adjustment costs. Conversely, the stickier components of the CPI (durable industrial goods and services) exhibit very low idiosyncratic and common shocks, often in addition to large adjustment costs.

Another important feature of our model is the use of stochastically varying inaction thresholds following Caballero and Engel (2006). This feature helps to explain some of the stylized facts of price setting practices (seasonal pricing, heterogeneity in price stickiness across outlets in terms, synchronization of price changes across and within stores).

Our results also strongly favor the introduction of heterogenous price behaviors in macroeconomic models. Two recent papers examine the implications of heterogeneity of (Calvo) pricing for the New Keynesian Phillips Curve. Using sectoral data on prices 
and marginal costs, Imbs et al. (2006) show that estimates of the NKPC that do not account for industry-level heterogeneity substantially overestimate the backward looking component, and slightly underestimate the role of marginal costs on inflation. In a multi-sector general equilibrium model, Carvalho (2006) shows that under heterogeneous pricing, monetary policy has larger and more persistent real effects than those predicted by single-firm models. In contradiction to the existing view on this issue (Bils and Klenow, 2004, Dhyne et al., 2006), our results indicate that heterogeneity across firms (or product categories) should not necessarily be introduced only through different degrees of nominal/intrinsic rigidity, but also through differences in extrinsic rigidities. 


\section{References}

[1] Álvarez, Luis J., Emmanuel Dhyne, Marco M. Hoeberichts, Claudia Kwapil, Hervé Le Bihan, Patrick Lünnemann, Fernando Martins, Roberto Sabbatini, Harald Stahl, Philip Vermeulen and Jouko Vilmunen, (2006) : "Sticky prices in the euro area: a summary of new micro evidence", Journal of the European Economic Association 4 $(2 / 3)$.

[2] Altissimo, Fillipo, Michael Erhmann and Frank Smets (2006): "Inflation persistence and price-setting behaviour in the euro area - a summary of the IPN evidence", ECB Occasional Paper No 46.

[3] Aucremanne, Luc and Emmanuel Dhyne (2004): "How Frequently Do Prices Change? Evidence Based on the Micro Data Underlying the Belgian CPI", ECB Working Paper Series No 331.

[4] Aucremanne, Luc and Martine Druant (2005): "Price setting behaviour in Belgium: what can be learned from an ad-hoc survey", ECB Working Paper Series, No 448

[5] Ball, Laurence, and Gregory Mankiw (1994): "Asymmetric Price Adjustment and Economic Fluctuations", Economic Journal 104, Mar. 1994, 247-261.

[6] Baudry, Laurent, Hervé Le Bihan, Patrick Sevestre, and Sylvie Tarrieu (2007): "What Do Thirteen Million Price Records Have to Say About Consumer Price Rigidity?", Oxford Bulletin of Economics and Statistics, 69, 139-183.

[7] Bils, Mark and Peter Klenow (2004): "Some Evidence on the Importance of Sticky Prices", Journal of Political Economy, 112, p 947-985.

[8] Blinder, Alan.S., Elie R. D. Canetti, David E. Lebow and Jeremy B. Rudd (1998), Asking About Prices: a New Approach to Undertsanding Price Stickiness, Russel Sage Foundation, New York

[9] Caballero Ricardo and Eduardo Engel (2006): "Price Stickiness in Ss Models: Basic Properties", mimeo

[10] Campbell Jeffrey R. and Benjamin Eden (2005): "Rigid prices: evidence from U.S. scanner data," Working Paper Series WP-05-08, Federal Reserve Bank of Chicago.

[11] Carvalho, Carlos (2006), Heterogeneity in Price Stickiness and the New Keynesian Phillips Curve, Princeton University, mimeo 
[12] Cecchetti, Stephen G., (1986), The Frequency of Price Adjustments: A Study of the Newsstand Price of Magazines, Journal of Econometrics, 31, 255-274.

[13] Cornille, David and Maarten Dossche (2006): "The Pattern and Determinants of Price Setting in the Belgian Industry", ECB Working Paper Series, No 618

[14] Dhyne, Emmanuel, Luis J. Álvarez, Hervé Le Bihan, Giovanni Veronese, Daniel Dias, Johannes Hoffmann, Nicole Jonker, Patrick Lünnemann, Fabio Rumler and Jouko Vilmunen, (2006) "Price Changes in the Euro Area and the United States: Some Facts from Individual Consumer Price Data", Journal of Economic Perspective, Vol $20 / 2$.

[15] Dotsey, Michael, Robert G. King, and Alexander L. Wolman (1999): "StateDependent Pricing and the General Equilibrium Dynamics of Money and Output", Quarterly Journal of Economics, 114, 655-690

[16] Fabiani, Silvia, Martine Druant, Ignacio Hernando, Claudia Kwapil, Betina Landau, Claire Loupias, Fernando Martins, Thomas Mathä, Roberto Sabbatini, and Ad Stokman (2005): "The Pricing Behaviour of Firms in the Euro Area: New Survey Evidence", ECB Working Paper Series No 535.

[17] Fougère, Denis, Hervé Le Bihan, and Patrick Sevestre (2007): "Heterogeneity in Price Stickiness: a Microeconometric Investigation", forthcoming in the Journal of Economic and Business Statistics.

[18] Gertler, Mark and John Leahy (2006): "A Phillips Curve with an Ss Foundation", NBER Working Paper No 11971

[19] Golosov, Mikhail and Robert E. Lucas (2003): "Menu Costs and Phillips Curves", NBER Working Paper No 10187

[20] Hall, Simon and Anthony Yates (1998): "Are there Downward nominal/intrinsic Rigidities in Product Markets?", Bank of England, Working Paper No. 80

[21] Imbs, Jean, Eric Jondeau, and Florian Pelgrin, (2006), Aggregating Phillips Curve, HEC Lausanne, mimeo

[22] Jonker, Nicole, Harry Blijenberg and Carsten Folkertsma (2004): "Empirical Analysis of Price Setting Behaviour in the Netherlands in the Period 1998-2003 Using Micro Data ", ECB Working Paper Series No 413. 
[23] Kashyap, Anil K. (1995): "Sticky Prices: New Evidence from Retail Catalogs", Quarterly Journal of Economics, 245-274.

[24] Klenow, Peter and Oleksiy Kryvtsov (2005): "State-Dependent or Time-Dependent Pricing: Does it Matter for Recent U.S. Inflation?", NBER Working Paper 11043.

[25] Lach Saul and Daniel Tsiddon (1992): "The Behaviour of Prices and Inflation: An Empirical Analysis of Disaggregated Price Data", Journal of Political Economy, 100, 349-389.

[26] Lach, Saul and Daniel Tsiddon (2005): "Small Price Changes and Menu Costs," mimeo

[27] Levy, Daniel, Mark Bergen, Shantanu Dutta and Robert Venables (1997) "The magnitude of menu costs: direct evidence from large U.S. supermarket chains", Quarterly Journal of Economics, 112(3), 791-825

[28] Levy, Daniel., Haipeng. Chen, Sourav Ray and Mark Bergen (2005), "Asymmetric price adjustment "in the small". An implication of rational inattention", mimeo

[29] Loupias Claire and Roland Ricart (2006), "Price-setting in the French manufacturing sector: new evidence from survey data," Revue d'Economie Politique, 117(4), 541554

[30] Loupias, Claire, Thomas Heckel and Patrick Sevestre (2007): "Costs, demand and producer price stickiness", mimeo, Banque de France.

[31] Mankiw, Gregory and Ricardo Reis (2002): "Sticky Information versus Sticky Prices: A Proposal to Replace the New Keynesian Phillips Curve", Quarterly Journal of Economics, 117, p 1295-1328.

[32] Midrigan, Virgiliu (2006): "Menu Costs, Multi-Product Firms, and Aggregate Fluctuations", Ohio State University, Mimeo

[33] Papke, Leslie E. and Jeffrey M. Wooldridge (1996) "Econometric Methods for Fractional Response with an Application to 401(K) Plan Participation Rates", Journal of Applied Econometrics, Vol. 11, N.6, p. 619-632.

[34] Pesaran, M. Hashem.(2004), General Diagnostic Tests for Cross Section Dependence in Panels, CESifo Working Paper Series No. 1229; IZA Discussion Paper No. 1240. 
[35] Pesaran, M. Hashem.(2006), Estimation and Inference in Large Heterogeneous Panels with a Multifactor Error Structure, Econometrica, 74(4), 967-1012

[36] Ratfai, Attila, (2006), Linking Individual and Aggregate Price Changes, Mimeo, forthcoming in Journal of Money, Credit and Banking

[37] Rosett, Richard, N. (1959), "A Statistical Model of Frictions in Economics", Econometrica, 27, 263-267

[38] Rotemberg, Julio J. (2003), "The benevolence of the baker: Fair pricing under treat of customer anger", mimeo

[39] Sabbatini, Roberto, Silvia Fabiani, Angela Gatulli. and Giovanni.Veronese (2005), "Producer price behaviour in Italy : Evidence from micro PPI data", Banca d'Italia, mimeo

[40] Sheshinski, Eytan and Yoram Weiss, (1977), Inflation and costs of adjustment, Review of Economic Studies 44, 281-303.

[41] Sheshinski Eytan and Yoram Weiss, (1983), Optimal pricing policy under stochastic inflation, Review of Economic Studies 51, 513-529.

[42] Stahl, Harald (2005): "Time-dependent or state-dependent price setting ? Micro evidence from German metal-working industries", Deutsche Bundesbank Discussion Paper Series 1 : Economic Studies, No 25/2005

[43] Tsiddon, Daniel (1993), The (Mis)behaviour of the Price Level, Review of Economic Studies, 889-902.

[44] Veronese, Giovanni, Silvia Fabiani, Angela. Gattulli and Roberto Sabbatini (2005): "Consumer Price Behaviour In Italy: Evidence From Micro CPI Data", ECB Working Paper Series No 449.

[45] Yates, Anthony (1998): "Downward nominal/intrinsic Rigidity and Monetary Policy", Bank of England, Working Paper No. 82

[46] Zbaracki, Mark, Mark Ritson, Daniel Levy, Shantanu Dutta and Mark Bergen (2004): "Managerial and Customer Costs of Price Adjustment: Direct Evidence from Industrial Markets," Review of Economics and Statistics, Volume 86, No. 2, May 2004, 514-533. 
Appendix A: Mathematical Proofs

Proof of the first part of Lemma 1.

$$
E[y I(y+a)]=\sigma \phi\left(\frac{a+\mu}{\sigma}\right)+\mu \Phi\left(\frac{a+\mu}{\sigma}\right) .
$$

$$
\begin{aligned}
E[y I(y+a)] & =\int_{-a}^{+\infty} y \frac{1}{\sigma \sqrt{2 \pi}} e^{-\frac{1}{2}\left(\frac{y-\mu}{\sigma}\right)^{2}} d y \\
& =\int_{-a}^{+\infty} \frac{y-\mu}{\sigma} \frac{1}{\sqrt{2 \pi}} e^{-\frac{1}{2}\left(\frac{y-\mu}{\sigma}\right)^{2}} d y+\int_{-a}^{+\infty} \frac{\mu}{\sigma} \frac{1}{\sqrt{2 \pi}} e^{-\frac{1}{2}\left(\frac{y-\mu}{\sigma}\right)^{2}} d y
\end{aligned}
$$

Letting $z=(y-\mu) / \sigma$, the above expression becomes

$$
\begin{aligned}
E[y I(y+a)] & =\sigma \int_{-\frac{a+\mu}{\sigma}}^{+\infty} z \frac{1}{\sqrt{2 \pi}} e^{-\frac{1}{2} z^{2}} d z+\mu \int_{-\frac{a+\mu}{\sigma}}^{+\infty} \frac{1}{\sqrt{2 \pi}} e^{-\frac{1}{2} z^{2}} d z \\
& =\sigma\left[-\frac{1}{\sqrt{2 \pi}} e^{-\frac{1}{2} z^{2}}\right]_{-\frac{a+\mu}{\sigma}}^{+\infty}+\mu \int_{-\infty}^{\frac{a+\mu}{b}} \frac{1}{\sqrt{2 \pi}} e^{-\frac{1}{2} z^{2}} d z \\
& =\sigma \phi\left(\frac{a+\mu}{\sigma}\right)+\mu \Phi\left(\frac{a+\mu}{\sigma}\right)
\end{aligned}
$$

Proof of the second part of Lemma 1.

$$
E\left[\phi\left(\frac{y+a}{b}\right)\right]=\frac{b}{\sqrt{b^{2}+\sigma^{2}}} \phi\left(\frac{a+\mu}{\sqrt{b^{2}+\sigma^{2}}}\right)
$$




$$
\begin{aligned}
E\left[\phi\left(\frac{y+a}{b}\right)\right] & =\int_{-\infty}^{+\infty} \frac{1}{\sqrt{2 \pi}} e^{-\frac{1}{2}\left(\frac{y+a}{b}\right)^{2}} \frac{1}{\sigma \sqrt{2 \pi}} e^{-\frac{1}{2}\left(\frac{y-\mu}{\sigma}\right)^{2}} d y \\
& =\frac{1}{\sigma^{2} \pi} \int_{-\infty}^{+\infty} e^{-\frac{1}{2}\left(\frac{\left(\sigma^{2}+b^{2}\right) y^{2}+\left(2 a \sigma^{2}-2 b^{2} \mu\right) y+a^{2} \sigma^{2}+b^{2} \mu^{2}}{b^{2} \sigma^{2}}\right)} d y \\
& =\frac{1}{\sigma^{2} \pi} \int_{-\infty}^{+\infty} e^{-\frac{1}{2}\left(\frac{\left(\sqrt{\sigma^{2}+b^{2}} y+A\right)^{2}-A^{2}+a^{2} \sigma^{2}+b^{2} \mu^{2}}{b^{2} \sigma^{2}}\right)} d y
\end{aligned}
$$

where $A=\frac{a \sigma^{2}-\mu b^{2}}{\sqrt{b^{2}+\sigma^{2}}}$.

Let $B=\frac{1}{2}\left(\frac{A^{2}-a^{2} \sigma^{2}-b^{2} \mu^{2}}{b^{2} \sigma^{2}}\right)=-\frac{1}{2} \frac{(a+\mu)^{2}}{b^{2}+\sigma^{2}}$,

$$
\begin{aligned}
E\left[\phi\left(\frac{y+a}{b}\right)\right] & =\frac{1}{\sigma^{2} \pi} e^{B} \int_{-\infty}^{+\infty} e^{-\frac{1}{2}\left(\frac{\left(\sqrt{\sigma^{2}+b^{2}} y+A\right)^{2}}{b^{2} \sigma^{2}}\right)} d y \\
& =\frac{1}{\sigma^{2} \pi} e^{B} \int_{-\infty}^{+\infty} e^{-\frac{1}{2} \frac{\sigma^{2}+b^{2}}{b^{2} \sigma^{2}}\left(y+\frac{a \sigma^{2}-\mu b^{2}}{b^{2}+\sigma^{2}}\right)^{2}} d y
\end{aligned}
$$

Setting $\omega=\frac{b \sigma}{\sqrt{b^{2}+\sigma^{2}}}$ and $\widetilde{\mu}=-\frac{a \sigma^{2}-\mu b^{2}}{b^{2}+\sigma^{2}}$, we now have

$$
\begin{aligned}
E\left[\phi\left(\frac{y+a}{b}\right)\right] & =\frac{1}{\sigma^{2} \pi} e^{B} \int_{-\infty}^{+\infty} e^{-\frac{1}{2 \omega^{2}}(y-\widetilde{\mu})^{2}} d y \\
& =\frac{1}{\sigma^{2} \pi} e^{B} \omega \sqrt{2 \pi}=\frac{b}{\sqrt{b^{2}+\sigma^{2}}} \frac{1}{\sqrt{2 \pi}} e^{B} \\
& =\frac{b}{\sqrt{b^{2}+\sigma^{2}}} \phi\left(\frac{a+\mu}{\sqrt{b^{2}+\sigma^{2}}}\right)
\end{aligned}
$$

Proof of the third part of Lemma 1.

$$
E\left(\Phi\left(\frac{y+a}{b}\right)\right)=\Phi\left(\frac{a+\mu}{\sqrt{b^{2}+\sigma^{2}}}\right)
$$




$$
E\left[\Phi\left(\frac{y+a}{b}\right)\right]=\int_{-\infty}^{+\infty} \int_{-\infty}^{\frac{y+a}{b}} \frac{1}{\sqrt{2 \pi}} e^{-\frac{1}{2} w} \frac{1}{\sigma \sqrt{2 \pi}} e^{-\frac{1}{2}\left(\frac{y-\mu}{\sigma}\right)^{2}} d w d y
$$

Stating that $\frac{z+y+a}{b}=w$, the expression above becomes

$$
\begin{aligned}
E\left[\Phi\left(\frac{y+a}{b}\right)\right] & =\int_{-\infty}^{+\infty} \int_{-\infty}^{0} \frac{1}{b \sqrt{2 \pi}} e^{-\frac{1}{2}\left(\frac{z+y+a}{b}\right)^{2}} \frac{1}{\sigma \sqrt{2 \pi}} e^{-\frac{1}{2}\left(\frac{y-\mu}{\sigma}\right)^{2}} d z d y \\
& =\int_{-\infty}^{0} \frac{1}{b} \int_{-\infty}^{+\infty} \frac{1}{\sqrt{2 \pi}} e^{-\frac{1}{2}\left(\frac{z+y+a}{b}\right)^{2}} \frac{1}{\sigma \sqrt{2 \pi}} e^{-\frac{1}{2}\left(\frac{y-\mu}{\sigma}\right)^{2}} d y d z \\
& =\int_{-\infty}^{0} \frac{1}{b} E\left[\phi\left(\frac{y+a+z}{b}\right)\right] d z
\end{aligned}
$$

Using the second part of Lemma 1,

$$
\begin{aligned}
E\left[\Phi\left(\frac{y+a}{b}\right)\right] & =\int_{-\infty}^{0} \frac{1}{b} \frac{b}{\sqrt{b^{2}+\sigma^{2}}} \phi\left(\frac{z+a+\mu}{\sqrt{b^{2}+\sigma^{2}}}\right) d z \\
& =\frac{1}{\sqrt{b^{2}+\sigma^{2}}} \int_{-\infty}^{0} \frac{1}{\sqrt{2 \pi}} e^{-\frac{1}{2}\left(\frac{z+a+\mu}{\sqrt{b^{2}+\sigma^{2}}}\right)^{2}} d z
\end{aligned}
$$

Setting $\frac{z+a+\mu}{\sqrt{b^{2}+\sigma^{2}}}=\widetilde{z}$

$$
\begin{aligned}
E\left[\Phi\left(\frac{y+a}{b}\right)\right] & =\frac{1}{\sqrt{b^{2}+\sigma^{2}}} \int_{-\infty}^{\frac{a+\mu}{\sqrt{b^{2}+\sigma^{2}}}} \frac{\sqrt{b^{2}+\sigma^{2}}}{\sqrt{2 \pi}} e^{-\frac{1}{2} \widetilde{z}^{2}} d \widetilde{z} \\
& =\Phi\left(\frac{a+\mu}{\sqrt{b^{2}+\sigma^{2}}}\right)
\end{aligned}
$$

Proof of the uniqueness of $\tilde{f}_{t}$ (the non-linear cross section average estimator of $f_{t}$ ). Let

$$
z_{i t}\left(f_{t}\right)=\frac{d_{i t}}{\sqrt{\sigma_{c}^{2}+\sigma_{\xi}^{2}}}
$$


and

$$
\begin{aligned}
\widetilde{\Delta p}_{i t} & =\frac{\Delta p_{i t}}{\sqrt{\sigma_{c}^{2}+\sigma_{\xi}^{2}}}, \tilde{\eta}_{i t}=\frac{\eta_{i t}}{\sqrt{\sigma_{c}^{2}+\sigma_{\xi}^{2}}}, \\
\tilde{c} & =\frac{c}{\sqrt{\sigma_{c}^{2}+\sigma_{\xi}^{2}}} \geq 0, \delta^{2}=\frac{\sigma_{\xi}^{2}}{\sigma_{c}^{2}+\sigma_{\xi}^{2}}<1,
\end{aligned}
$$

and note that we have

$$
\begin{aligned}
\widetilde{\Delta p_{i t}}= & z_{i t}\left(f_{t}\right)+z_{i t}\left(f_{t}\right)\left[\Phi\left(z_{i t}\left(f_{t}\right)-\tilde{c}\right)-\Phi\left(z_{i t}\left(f_{t}\right)+\tilde{c}\right)\right] \\
& +\delta^{2}\left[\phi\left(z_{i t}\left(f_{t}\right)-\tilde{c}\right)-\phi\left(z_{i t}\left(f_{t}\right)+\tilde{c}\right)\right]+\tilde{\eta}_{i t} .
\end{aligned}
$$

The cross-sectional average estimate of $f_{t}$ is now given by the solution of the non-linear equation

$$
\begin{aligned}
\Psi\left(\tilde{f}_{t}\right)= & \sum_{i=1}^{N} w_{i t}\left\{z_{i t}\left(\tilde{f}_{t}\right)+z_{i t}\left(\tilde{f}_{t}\right)\left[\Phi\left(z_{i t}\left(\tilde{f}_{t}\right)-\tilde{c}\right)-\Phi\left(z_{i t}\left(\tilde{f}_{t}\right)+\tilde{c}\right)\right]\right. \\
& \left.\quad+\delta^{2}\left[\phi\left(z_{i t}\left(\tilde{f}_{t}\right)-\tilde{c}\right)-\phi\left(z_{i t}\left(\tilde{f}_{t}\right)+\tilde{c}\right)\right]\right\}-a_{N t} \\
= & 0,
\end{aligned}
$$

where $a_{N t}=\sum_{i=1}^{N} w_{i t} \widetilde{\Delta p}_{i t}$.

First it is clear that $\Psi\left(\tilde{f}_{t}\right)$ is a continuous and differentiable function of $f_{t}$, and it is now easily seen that

$$
\lim _{f_{t} \rightarrow+\infty} \Psi\left(\tilde{f}_{t}\right) \rightarrow+\infty \text { and } \lim _{f_{t} \rightarrow-\infty} \Psi\left(\tilde{f}_{t}\right) \rightarrow-\infty
$$

Also the first derivative of $\Psi\left(f_{t}\right)$ is given by ${ }^{29}$

$$
\Psi^{\prime}\left(\tilde{f}_{t}\right)=\frac{1}{\sqrt{\sigma_{c}^{2}+\sigma_{\xi}^{2}}} \sum_{i=1}^{N} w_{i t} q_{i t}
$$

where

$$
q_{i t}=1+\Phi\left(z_{i t}\left(\tilde{f}_{t}\right)-\tilde{c}\right)-\Phi\left(z_{i t}\left(\tilde{f}_{t}\right)+\tilde{c}\right)+\left(1-\delta^{2}\right) h\left(z_{i t}\left(\tilde{f}_{t}\right)\right),
$$

\footnotetext{
${ }^{29}$ Recall that the weights, $w_{i t}$, are non-zero pre-determined constants, and in particular do not depend on $f_{t}$.
} 
and

$$
h\left(z_{i t}\left(\tilde{f}_{t}\right)\right)=z_{i t}\left(\tilde{f}_{t}\right)\left[\phi\left(z_{i t}\left(\tilde{f}_{t}\right)-\tilde{c}\right)-\phi\left(z_{i t}\left(\tilde{f}_{t}\right)+\tilde{c}\right)\right] .
$$

But since $1-\Phi\left(z_{i t}\left(\tilde{f}_{t}\right)+\tilde{c}\right)=\Phi\left(-z_{i t}\left(\tilde{f}_{t}\right)-\tilde{c}\right)$, then

$$
1+\Phi\left(z_{i t}\left(\tilde{f}_{t}\right)-\tilde{c}\right)-\Phi\left(z_{i t}\left(\tilde{f}_{t}\right)+\tilde{c}\right)=\Phi\left(z_{i t}\left(\tilde{f}_{t}\right)-\tilde{c}\right)+\Phi\left(-z_{i t}\left(\tilde{f}_{t}\right)-\tilde{c}\right)>0
$$

and it is easily seen that $h\left(z_{i t}\left(\tilde{f}_{t}\right)\right)$ is symmetric, namely $h\left(z_{i t}\left(\tilde{f}_{t}\right)\right)=h\left(-z_{i t}\left(\tilde{f}_{t}\right)\right)$. Focusing on the non-negative values of $z_{i t}\left(\tilde{f}_{t}\right)$ it is easily seen that

$$
\left.h\left(z_{i t}\right)\right)=\frac{z_{i t}}{\sqrt{2 \pi}}\left[e^{-0.5\left(z_{i t}-\tilde{c}\right)^{2}}-e^{-0.5\left(z_{i t}+\tilde{c}\right)^{2}}\right]>0 \text { for } \tilde{c}>0
$$

and by symmetry $\left.h\left(z_{i t}\right)\right) \geq 0$, for all $\tilde{c} \geq 0$. Hence, $q_{i t}>0$ for all $i$ and $t$, and $\tilde{c} \geq 0$. Therefore, it also follows that $\Psi^{\prime}\left(f_{t}\right)>0$, for all value of $w_{i t} \geq 0$ and $c \geq 0$. Thus, by the fixed point theorem, $\Psi\left(f_{t}\right)$ must cut the horizontal axis but only once.

Proof of the consistency of $\tilde{f}_{t}$ as an estimator of $f_{t}$ as $N \rightarrow \infty$.

Let

$$
\begin{gathered}
\Psi\left(f_{t}\right)=\sum_{i=1}^{N} w_{i t}\left\{z_{i t}\left(f_{t}\right)+z_{i t}\left(f_{t}\right)\left[\Phi\left(z_{i t}\left(f_{t}\right)-\tilde{c}\right)-\Phi\left(z_{i t}\left(f_{t}\right)+\tilde{c}\right)\right]\right. \\
\left.+\delta^{2}\left[\phi\left(z_{i t}\left(f_{t}\right)-\tilde{c}\right)-\phi\left(z_{i t}\left(f_{t}\right)+\tilde{c}\right)\right]\right\}-a_{N t}
\end{gathered}
$$

and note that

$$
\Psi\left(f_{t}\right)=-\sum_{i=1}^{N} w_{i t} \eta_{i t} .
$$

Consider now the mean-value expansion of $\Psi\left(f_{t}\right)$ around $\tilde{f}_{t}$

$$
\Psi\left(f_{t}\right)-\Psi\left(\tilde{f}_{t}\right)=\Psi^{\prime}\left(\bar{f}_{t}\right)\left(f_{t}-\tilde{f}_{t}\right)
$$

where $\bar{f}_{t}$ lies on the line segment between $f_{t}$ and $\tilde{f}_{t}$. Since $\Psi\left(\tilde{f}_{t}\right)=0$ and $\Psi^{\prime}\left(\bar{f}_{t}\right)>0$ for all $\bar{f}_{t}$ (as established above) we have

$$
\tilde{f}_{t}-f_{t}=\frac{-\sum_{i=1}^{N} w_{i t} \tilde{\eta}_{i t}}{\Psi^{\prime}\left(\bar{f}_{t}\right)}
$$

Recall that $\tilde{\eta}_{i t}=\left(\sigma_{c}^{2}+\sigma_{\xi}^{2}\right)^{-1 / 2}\left[\Delta p_{i t}-E\left(\Delta p_{i t} \mid \mathbf{h}_{i t}\right)\right]$, where $\mathbf{h}_{i t}=\left(f_{t}, \mathbf{x}_{i t}, p_{i, t-1}\right)$, and hence $E\left(\tilde{\eta}_{i t}\right)=0$. Further, conditional on $f_{t}$ and $\mathbf{x}_{i t}$, price changes, $\Delta p_{i t}$, being functions 
of independent shocks $v_{i}$ and $\varepsilon_{i t}$ over $i$, will be cross sectionally independent. Therefore, $\eta_{i t}$ will also be cross sectionally independent; although they need not be identically distributed even if the underlying shocks, $v_{i}$ and $\varepsilon_{i t}$, are identically distributed over $i$.

Given the above results we now have (for each $t$ and as $N \rightarrow \infty$ )

$$
\left(\sum_{i=1}^{N} w_{i t}^{2}\right)^{-1 / 2}\left(\tilde{f}_{t}-f_{t}\right) \backsim N\left(0, \vartheta_{\tilde{f}}^{2}\right),
$$

where

$$
\vartheta_{\tilde{f}}^{2}=\lim _{N \rightarrow \infty}\left\{\frac{\left(\sum_{i=1}^{N} w_{i t}^{2}\right)^{-1} \sum_{i=1}^{N} w_{i t}^{2} \operatorname{Var}\left(\tilde{\eta}_{i t}\right)}{\left[\Psi^{\prime}\left(f_{t}\right)\right]^{2}}\right\}
$$

Note that as $N \rightarrow \infty, \sum_{i=1}^{N} w_{i t} \tilde{\eta}_{i t} \stackrel{p}{\rightarrow} 0$, and hence $\tilde{f}_{t} \stackrel{p}{\rightarrow} f_{t}$, since $\Psi^{\prime}\left(f_{t}\right)>0$ for all $f_{t}$.It must also be that $\bar{f}_{t} \stackrel{p}{\rightarrow} f_{t}$.

In the case where $w_{i t}=1 / N$, we have

$$
\vartheta_{\tilde{f}}^{2}=\lim _{N \rightarrow \infty}\left\{\frac{N^{-1} \sum_{i=1}^{N} \operatorname{Var}\left(\tilde{\eta}_{i t}\right)}{\left[\Psi^{\prime}\left(f_{t}\right)\right]^{2}}\right\} .
$$

It also follows that $\tilde{f}_{t}-f_{t}=O_{p}\left(N^{-1 / 2}\right)$. 


\section{Appendix B: Data Sources}

\section{The Belgian CPI data set :}

The Belgian CPI data set contains monthly individual price reports collected by the Federal Public Service "Economy, SMEs, Self-Employed and Energy" for the computation of the Belgian National and Harmonized Index of Consumer Prices. In its complete version, it covers the 1989:01 - 2005:12 period. Considering the whole sample, would have involved analyzing more than 20,000,000 price records. For this project, we restricted the analysis to the product categories included in the Belgian CPI basket for the base year 1996, and restricted our period of observation to the 1994:07 - 2003:02 period. Our data set covers only the product categories for which the prices are recorded throughout the entire year in a decentralized way, i.e. $65.5 \%$. of the Belgian CPI basket for the base year 1996. The remaining $34.5 \%$ relate to product categories that are monitored centrally by the Federal Public Services, such as housing rents, electricity, gas, telecommunications, health care, newspapers and insurance services and to product categories that are not available for sale during the entire year (some fruits and vegetables, winter and summer fees in tennis club). Price reports take into account all types of rebates and promotions, except those relating to the winter and summer sales period, which typically take place in January and July. In addition to the price records, the Belgian CPI data sets provides information on the location of the seller, a seller identifier, the packaging of the product (in order to identify promotions in quantity) and the brand of the product. For all products, the price concept used in this paper correspond to the log of price per unit.

\section{The French CPI data set :}

The French CPI data set contains more than 13,000,000 monthly individual price records collected by the INSEE for the computation of the French National and Harmonized Index of Consumer Prices. It covers the period July 1994:07 - February 2003. This data set covers $65.5 \%$. of the French CPI basket. Indeed, the prices of some categories of goods and services are not available in our sample: centrally collected prices - of which major items are car prices and administered or public utility prices (e.g. electricity)- as well as other types of products such as fresh food and rents. At the COICOP 5-digit level, we have access to 128 product categories out of 160 in the CPI. As a result, the coverage rate is above $70 \%$ for food and non-energy industrial goods, but closer to $50 \%$ in the services, since a large part of services prices are centrally collected, e.g. for transport or administrative or financial services.

Each individual price quote consists of the exact price level of a precisely defined product. What is meant by "product" is a particular product, of a particular brand 
and quality, sold in a particular outlet. The individual product identification number allows us to follow the price of a product through time, and to recover information on the type of outlet (hypermarket, supermarket, department store, specialized store, corner shop, service shop, etc.), the category of product and the regional area where the outlet is located (for confidentiality reasons, a more precise location of outlets was not made available to us). The sequences of records corresponding to such defined individual products are referred to as price trajectories. Importantly, if in a given outlet a given product is definitively replaced by a similar product of another brand or of a different quality, a new identification number is created, and a new price trajectory is started. On top of the above mentioned information, the following additional information is recorded : the year and month of the record, a qualitative "type of record" code and (when relevant) the quantity sold. When relevant, division by the indicator of the quantity is used in order to recover a consistent price per unit. The "type of record" code indicates the nature of the price recorded: regular price, sales or rebates, or "pseudo-observation" (a "pseudoobservation" is essentially an observation which has been imputed by the INSEE; see Baudry et al. (2004) for more details on the way we have tackled such imputed values to avoid creating "false" price changes).

\section{Confidentiality data restrictions}

Due to strong confidentiality restrictions, we are not allowed to provide anyone with the micro price reports underlying this work. However, a data set containing simulated data and the MatLab code of the estimation procedures are available on request (emmanuel.dhyne@nbb.be). A SAS code is also available.

\section{Appendix C - Detailed Results}

Description of Tables $A$ and $B$

Columns (2) to (6) refer to the results obtained by Full ML :

- $c$ represents the estimated value of the average menu cost ;

- $\operatorname{sig}_{e}$ represents the estimated value of $\sigma_{\varepsilon}$;

- $s i g_{c}$ represents the estimated value of $\sigma_{c}$;

- $\operatorname{sig}_{u}$ represents the estimated value of $\sigma_{\nu}$;

- Logl represents the maximized value of the likelihood function ;

Columns (7) and (8) refer to the results associated to the time-series representation of $f_{t}$. 
- sig $_{\omega}$ represents the estimated value of $\sigma_{\omega}$;

- $S\left(r h o_{k}\right)$ represents the estimated value of $\bar{\rho}=\sum_{i=1}^{K} \rho_{i}$

Column (9) present the correlation between $f_{t}$ and the log of the product category price index.

Columns (10) to (13) provide descriptive statistics of the data set (the average number of observations each month, Nbar, the frequency of price changes, Freq, the average size of price changes in absolute term, $|D p|$, and the share of price increases, \%up.

Columns (14) to (16) provide averages of the frequency of price changes, Freq* the average size of price changes in absolute term, $|D p|^{*}$, and the share of price increases, $\% u p^{*}$ obtained on the basis of simulated data generated using the estimated structural parameters and the estimated $f_{t}$ of each product categories. The simulation exercise is replicated 1000 times.

Grey cells indicate product categories for which the model fits the data poorly (low correlation of $f_{t}$ with the $\log$ of price index or with $\bar{p}_{t}$ or poor replication of the data characteristics by simulated data).

Description of Tables $C$ and $D$

Columns (2) to (8) provide basic statistics describing the estimated $f_{t}$ :

- $\sigma_{f}$ represents the unconditional standard deviation;

- $r_{i}$ represents the autocorrelation of order i. 


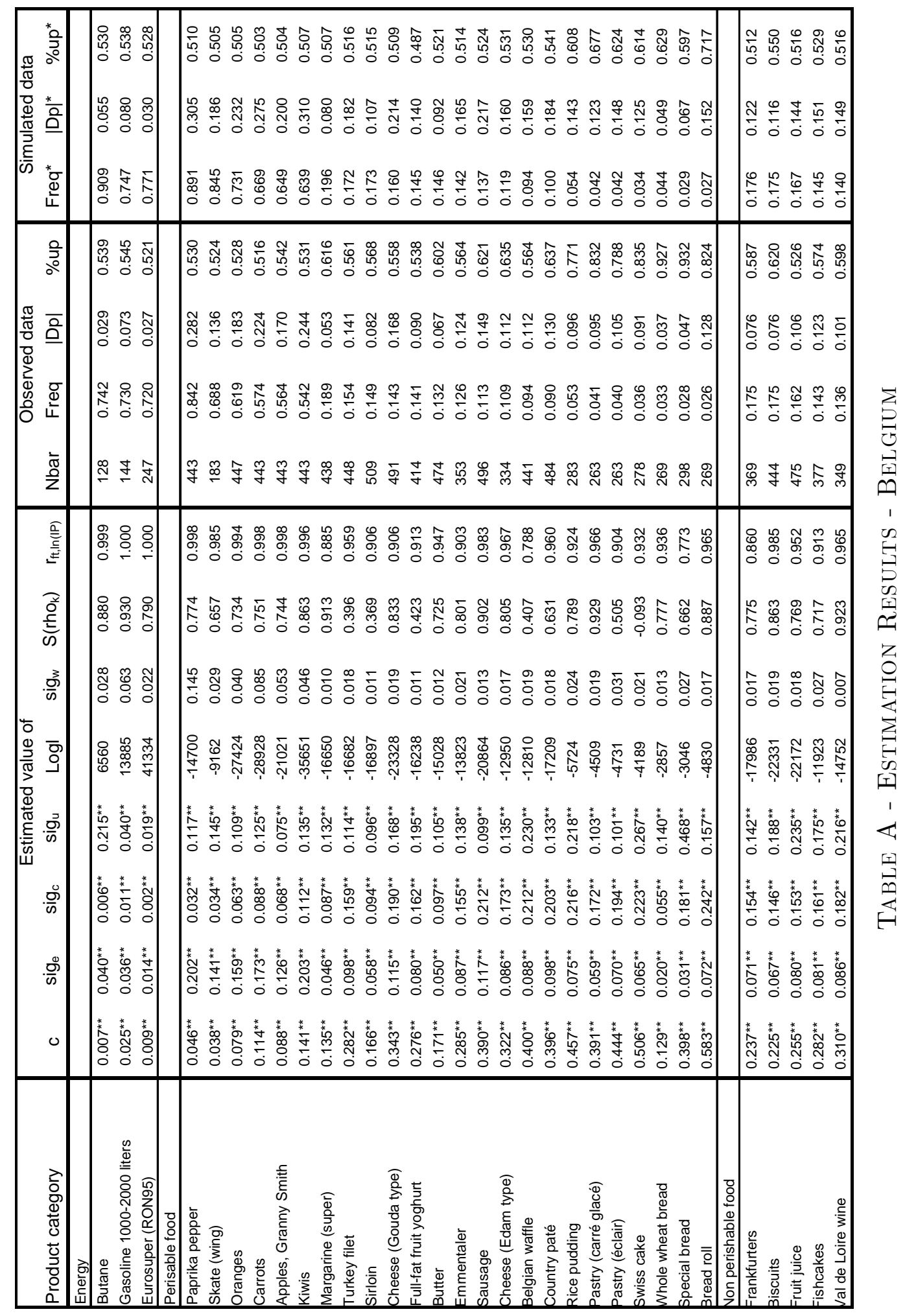




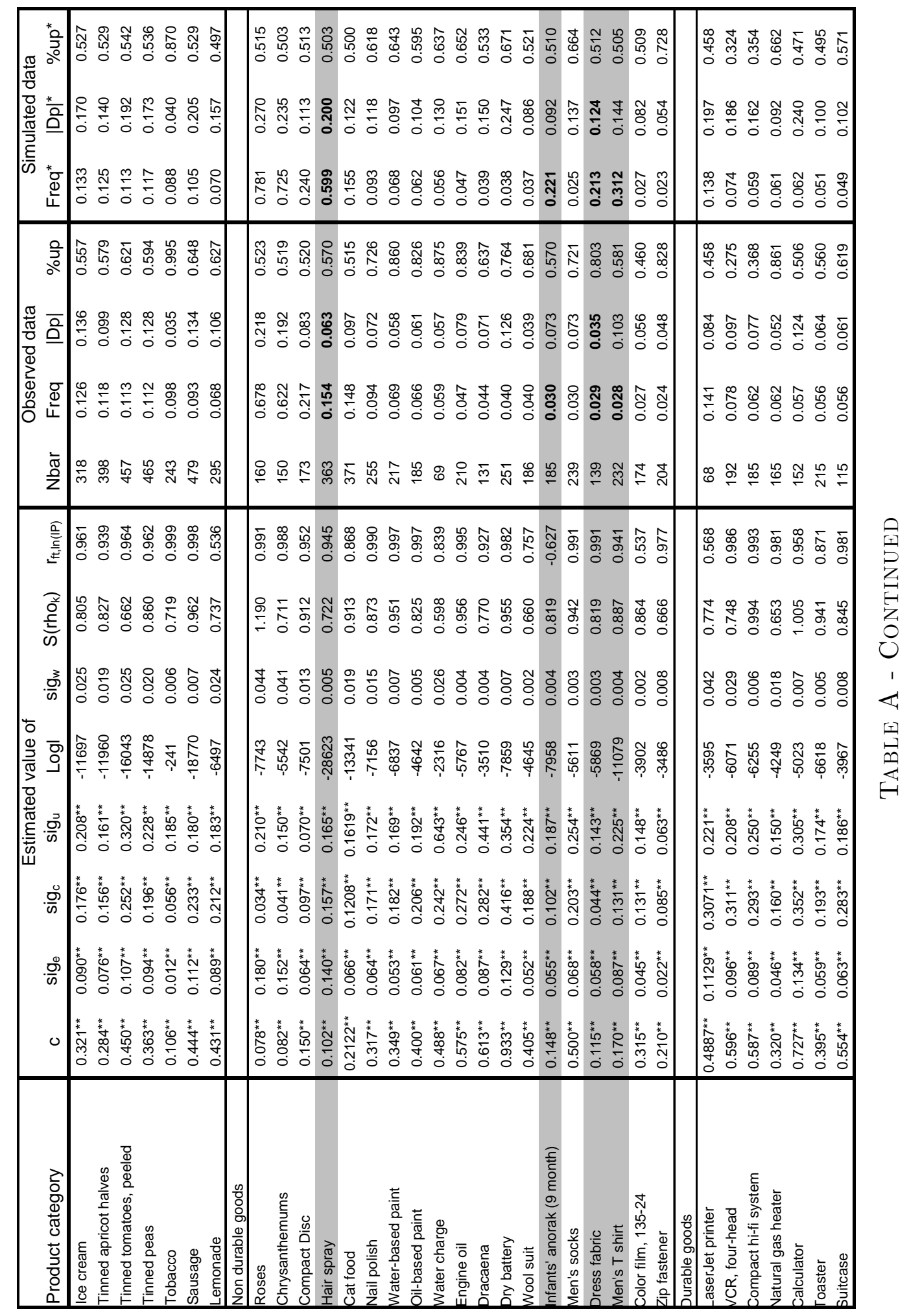




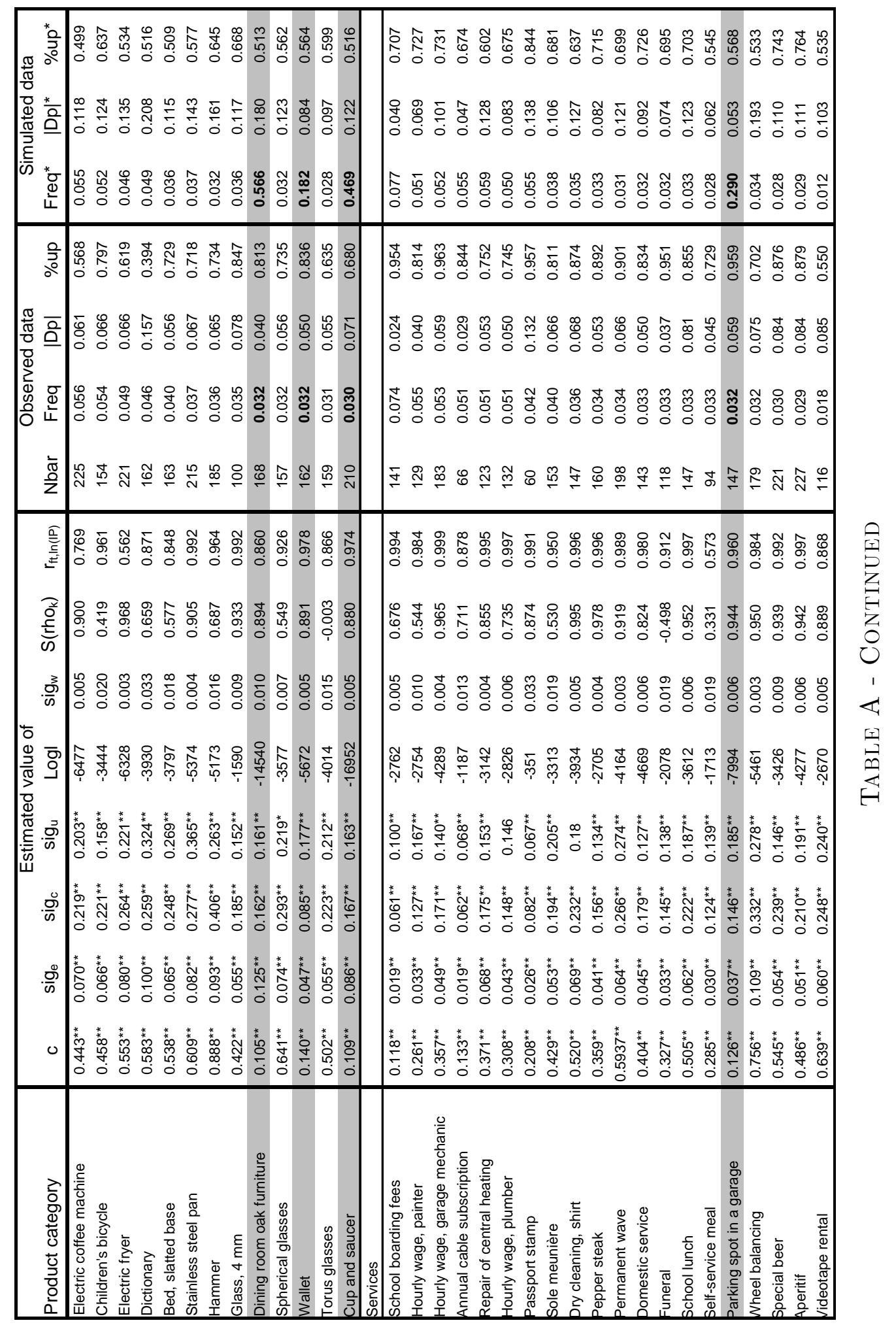




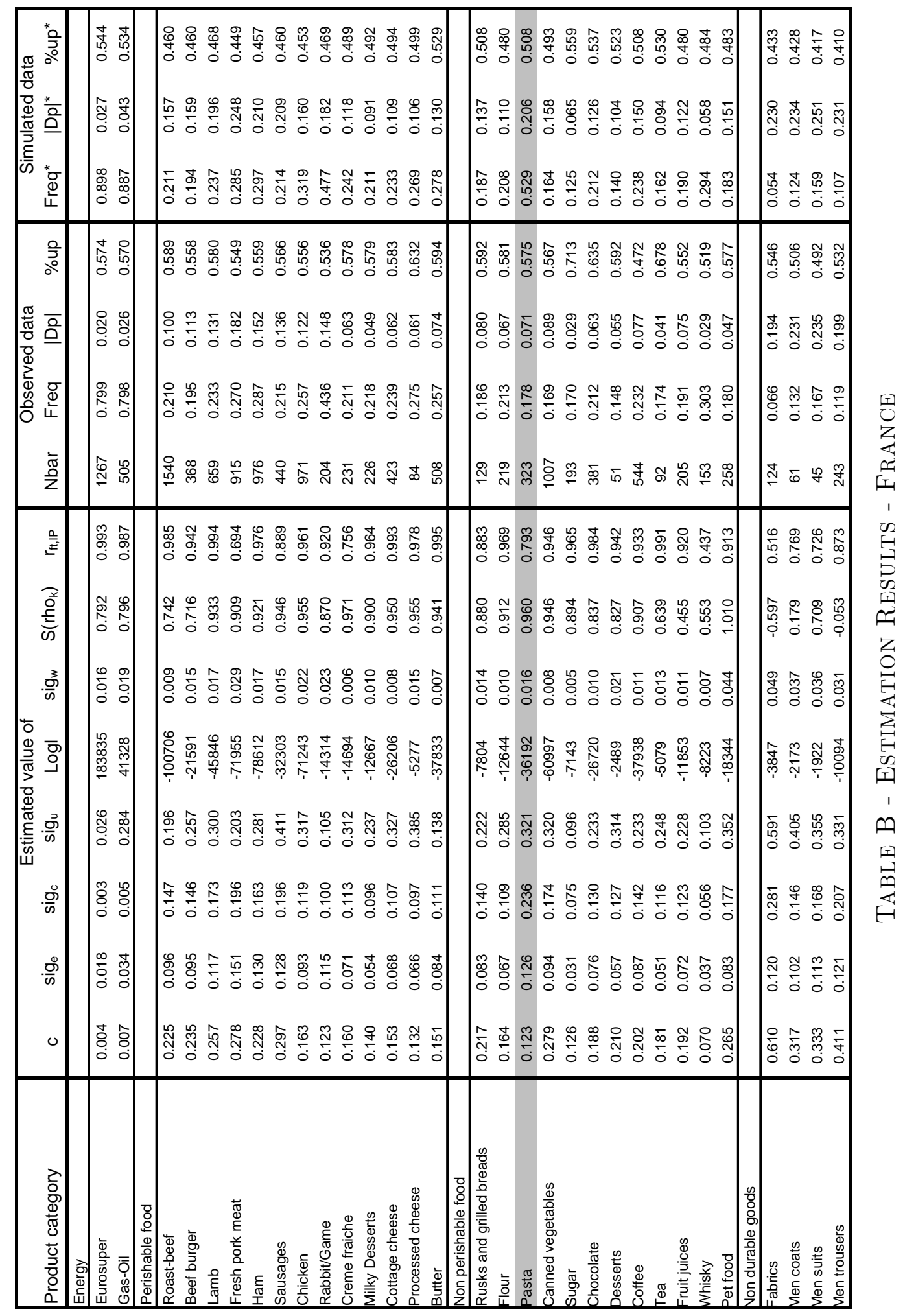




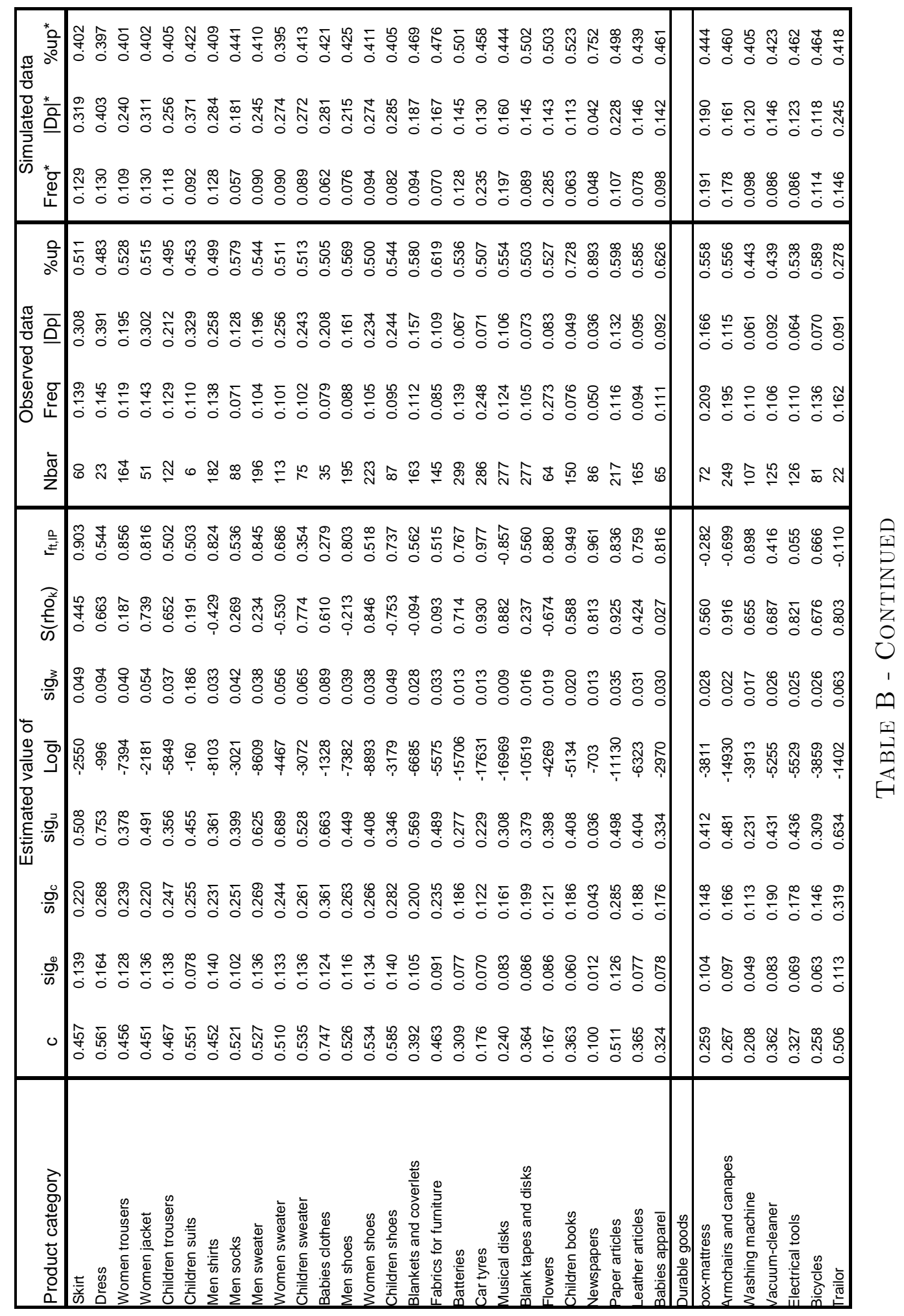




\begin{tabular}{|c|c|c|}
\hline 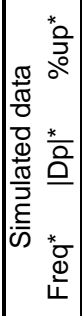 & 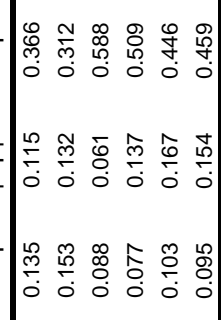 & 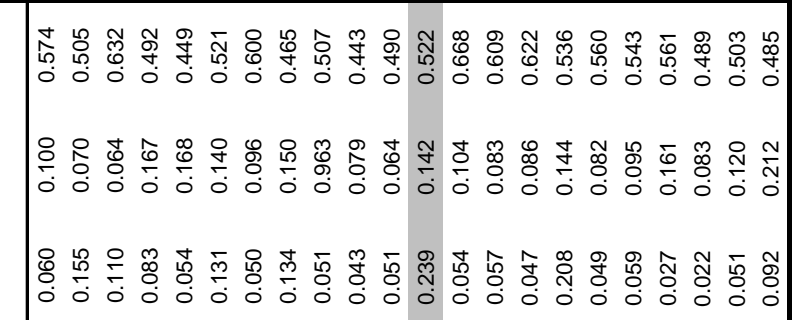 \\
\hline 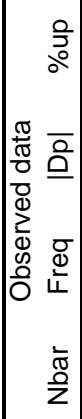 & 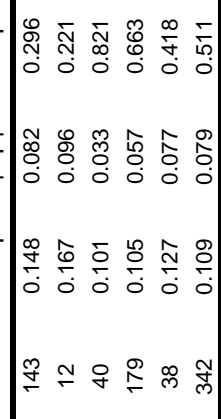 & 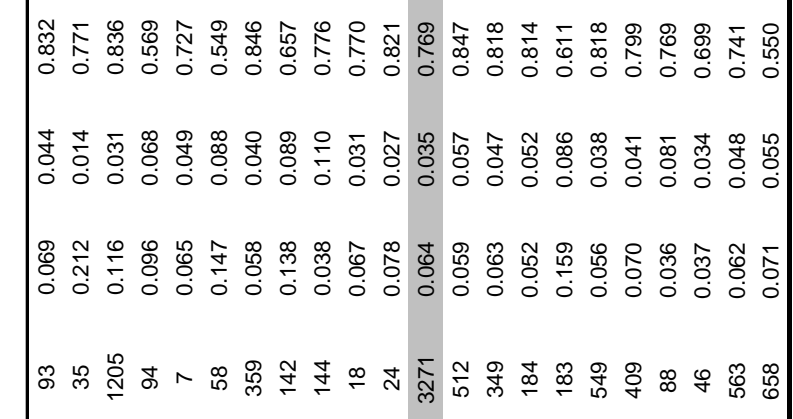 \\
\hline 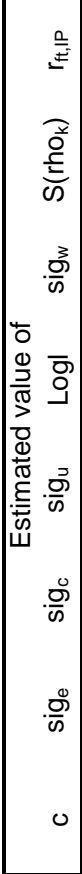 & 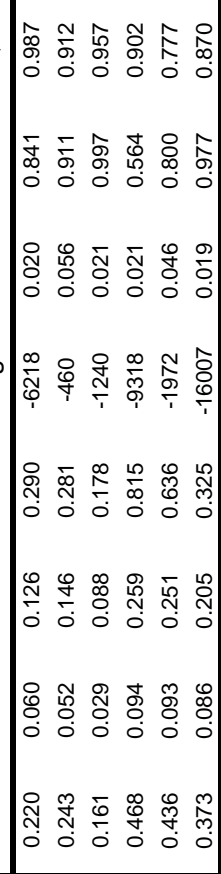 & 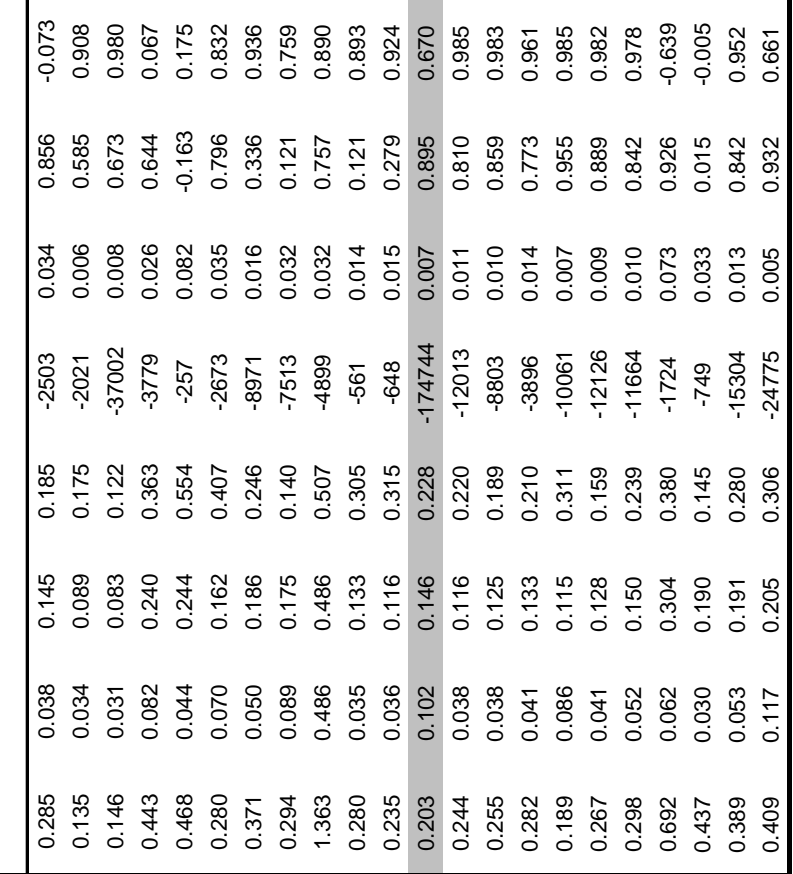 \\
\hline 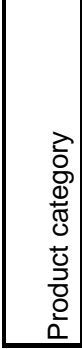 & 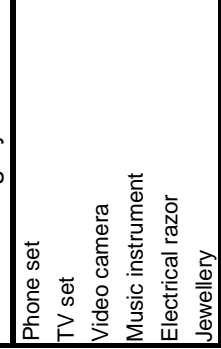 & 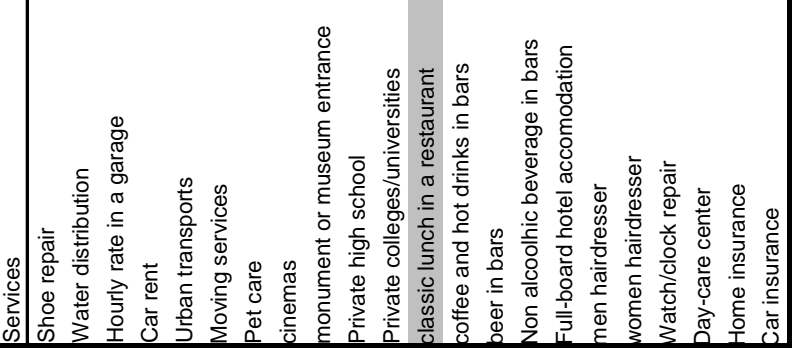 \\
\hline
\end{tabular}




\begin{tabular}{|c|c|c|c|c|c|c|c|}
\hline Product category & $\Xi_{f}$ & $\mathrm{r} 1$ & r2 & r3 & 14 & $\mathrm{r6}$ & $\mathrm{r} 12$ \\
\hline \multicolumn{8}{|l|}{ Energy } \\
\hline Butane & 0.153 & 0.983 & 0.959 & 0.937 & 0.918 & 0.890 & 0.801 \\
\hline Gasoline 1000-2000 liters & 0.263 & 0.973 & 0.939 & 0.905 & 0.867 & 0.799 & 0.501 \\
\hline Eurosuper (RON95) & 0.114 & 0.978 & 0.954 & 0.935 & 0.909 & 0.855 & 0.692 \\
\hline \multicolumn{8}{|l|}{ Perisable food } \\
\hline Paprika pepper & 0.249 & 0.685 & 0.288 & 0.003 & -0.131 & -0.440 & 0.715 \\
\hline Skate (wing) & 0.072 & 0.843 & 0.815 & 0.764 & 0.716 & 0.649 & 0.830 \\
\hline Oranges & 0.111 & 0.881 & 0.660 & 0.423 & 0.242 & 0.081 & 0.745 \\
\hline Carrots & 0.179 & 0.861 & 0.626 & 0.399 & 0.214 & 0.059 & 0.231 \\
\hline Apples, Granny Smith & 0.140 & 0.885 & 0.678 & 0.515 & 0.404 & 0.266 & 0.612 \\
\hline Kiwis & 0.172 & 0.947 & 0.862 & 0.763 & 0.662 & 0.551 & 0.820 \\
\hline Margarine (super) & 0.024 & 0.896 & 0.830 & 0.779 & 0.776 & 0.748 & 0.500 \\
\hline Turkey filet & 0.046 & 0.893 & 0.867 & 0.872 & 0.860 & 0.801 & 0.677 \\
\hline Sirloin & 0.020 & 0.690 & 0.757 & 0.705 & 0.703 & 0.647 & 0.565 \\
\hline Cheese (Gouda type) & 0.035 & 0.709 & 0.789 & 0.714 & 0.755 & 0.705 & 0.479 \\
\hline Full-fat fruit yoghurt & 0.023 & 0.828 & 0.806 & 0.769 & 0.771 & 0.742 & 0.685 \\
\hline Butter & 0.030 & 0.889 & 0.873 & 0.883 & 0.872 & 0.841 & 0.732 \\
\hline Emmentaler & 0.037 & 0.638 & 0.651 & 0.761 & 0.664 & 0.657 & 0.491 \\
\hline Sausage & 0.062 & 0.978 & 0.963 & 0.946 & 0.927 & 0.891 & 0.777 \\
\hline Cheese (Edam type) & 0.050 & 0.910 & 0.918 & 0.908 & 0.889 & 0.896 & 0.845 \\
\hline Belgian waffle & 0.027 & 0.526 & 0.615 & 0.502 & 0.515 & 0.438 & 0.387 \\
\hline Country paté & 0.063 & 0.935 & 0.934 & 0.936 & 0.931 & 0.918 & 0.884 \\
\hline Rice pudding & 0.059 & 0.852 & 0.836 & 0.868 & 0.864 & 0.854 & 0.780 \\
\hline Pastry (carré glacé) & 0.076 & 0.952 & 0.940 & 0.937 & 0.935 & 0.914 & 0.915 \\
\hline Pastry (éclair) & 0.070 & 0.829 & 0.827 & 0.858 & 0.799 & 0.814 & 0.793 \\
\hline Swiss cake & 0.054 & 0.827 & 0.859 & 0.852 & 0.848 & 0.860 & 0.790 \\
\hline Whole wheat bread & 0.030 & 0.870 & 0.866 & 0.861 & 0.851 & 0.827 & 0.716 \\
\hline Special bread & 0.037 & 0.576 & 0.639 & 0.597 & 0.619 & 0.596 & 0.422 \\
\hline Bread roll & 0.080 & 0.969 & 0.958 & 0.960 & 0.952 & 0.961 & 0.937 \\
\hline \multicolumn{8}{|l|}{ Non perishable food } \\
\hline Frankfurters & 0.035 & 0.868 & 0.796 & 0.767 & 0.715 & 0.656 & 0.333 \\
\hline Biscuits & 0.075 & 0.968 & 0.947 & 0.923 & 0.903 & 0.870 & 0.903 \\
\hline Fruit juice & 0.043 & 0.866 & 0.849 & 0.821 & 0.780 & 0.748 & 0.633 \\
\hline Fishcakes & 0.046 & 0.785 & 0.785 & 0.742 & 0.732 & 0.645 & 0.385 \\
\hline Val de Loire wine & 0.030 & 0.960 & 0.962 & 0.936 & 0.928 & 0.892 & 0.823 \\
\hline Ice cream & 0.085 & 0.950 & 0.939 & 0.920 & 0.902 & 0.865 & 0.816 \\
\hline Tinned apricot halves & 0.043 & 0.857 & 0.847 & 0.858 & 0.779 & 0.765 & 0.622 \\
\hline Tinned tomatoes, peeled & 0.075 & 0.937 & 0.913 & 0.896 & 0.890 & 0.831 & 0.784 \\
\hline Tinned peas & 0.062 & 0.920 & 0.912 & 0.905 & 0.865 & 0.836 & 0.715 \\
\hline Tobacco & 0.077 & 0.997 & 0.994 & 0.990 & 0.986 & 0.980 & 0.969 \\
\hline Sausage & 0.061 & 0.994 & 0.990 & 0.984 & 0.978 & 0.966 & 0.909 \\
\hline Lemonade & 0.026 & 0.124 & 0.211 & 0.331 & 0.359 & 0.344 & 0.183 \\
\hline \multicolumn{8}{|l|}{ Non durable goods } \\
\hline Roses & 0.139 & 0.665 & 0.410 & 0.209 & -0.104 & -0.548 & 0.936 \\
\hline Chrysanthemums & 0.126 & 0.784 & 0.432 & -0.015 & -0.425 & -0.887 & 0.914 \\
\hline Compact Disc & 0.029 & 0.860 & 0.827 & 0.814 & 0.796 & 0.797 & 0.654 \\
\hline Hair spray & 0.024 & 0.977 & 0.968 & 0.949 & 0.943 & 0.920 & 0.841 \\
\hline Cat food & 0.028 & 0.579 & 0.621 & 0.577 & 0.596 & 0.596 & 0.395 \\
\hline Nail polish & 0.088 & 0.978 & 0.970 & 0.965 & 0.960 & 0.969 & 0.960 \\
\hline Water-based paint & 0.074 & 0.995 & 0.989 & 0.983 & 0.978 & 0.967 & 0.920 \\
\hline bil-based paint & 0.055 & 0.994 & 0.990 & 0.985 & 0.979 & 0.970 & 0.953 \\
\hline Water charge & 0.080 & 0.879 & 0.886 & 0.890 & 0.868 & 0.834 & 0.811 \\
\hline Engine oil & 0.089 & 0.999 & 0.998 & 0.997 & 0.996 & 0.994 & 0.988 \\
\hline Pracaena & 0.019 & 0.969 & 0.962 & 0.948 & 0.946 & 0.929 & 0.889 \\
\hline Pry battery & 0.130 & 0.998 & 0.997 & 0.995 & 0.994 & 0.989 & 0.977 \\
\hline Wool suit & 0.006 & 0.880 & 0.803 & 0.779 & 0.745 & 0.642 & 0.643 \\
\hline 'nfants' anorak (9 month) & 0.015 & 0.958 & 0.939 & 0.917 & 0.899 & 0.869 & 0.823 \\
\hline Men's socks & 0.050 & 0.998 & 0.995 & 0.992 & 0.989 & 0.982 & 0.957 \\
\hline Press fabric & 0.027 & 0.993 & 0.989 & 0.986 & 0.981 & 0.977 & 0.956 \\
\hline Men's T shirt & 0.017 & 0.978 & 0.948 & 0.919 & 0.892 & 0.847 & 0.705 \\
\hline Color film, 135-24 & 0.005 & 0.842 & 0.835 & 0.772 & 0.682 & 0.624 & 0.530 \\
\hline Zip fastener & 0.034 & 0.968 & 0.958 & 0.951 & 0.941 & 0.937 & 0.901 \\
\hline
\end{tabular}

Table C - Statistical properties of the common component $\widehat{f}_{t}$ - Belgium 


\begin{tabular}{|c|c|c|c|c|c|c|c|}
\hline Product category & $\Xi_{f}$ & r1 & r2 & $r_{3}$ & 14 & r6 & $r 12$ \\
\hline \multicolumn{8}{|l|}{ Durable goods } \\
\hline LaserJet printer & 0.060 & 0.625 & 0.541 & 0.485 & 0.493 & 0.296 & -0.171 \\
\hline VCR, four-head & 0.177 & 0.979 & 0.969 & 0.964 & 0.968 & 0.978 & 0.974 \\
\hline Compact hi-fi system & 0.126 & 0.999 & 0.997 & 0.996 & 0.994 & 0.992 & 0.988 \\
\hline Natural gas heater & 0.092 & 0.979 & 0.966 & 0.961 & 0.957 & 0.947 & 0.949 \\
\hline Calculator & 0.053 & 0.991 & 0.980 & 0.971 & 0.961 & 0.937 & 0.864 \\
\hline Toaster & 0.013 & 0.935 & 0.866 & 0.814 & 0.744 & 0.611 & 0.215 \\
\hline Suitcase & 0.046 & 0.964 & 0.944 & 0.930 & 0.914 & 0.888 & 0.833 \\
\hline Electric coffee machine & 0.010 & 0.908 & 0.837 & 0.791 & 0.700 & 0.589 & 0.098 \\
\hline Children's bicycle & 0.070 & 0.947 & 0.922 & 0.917 & 0.925 & 0.916 & 0.882 \\
\hline Electric fryer & 0.017 & 0.979 & 0.953 & 0.928 & 0.900 & 0.827 & 0.585 \\
\hline Dictionary & 0.053 & 0.779 & 0.594 & 0.535 & 0.453 & 0.303 & 0.190 \\
\hline Bed, slatted base & 0.033 & 0.815 & 0.694 & 0.613 & 0.643 & 0.652 & 0.580 \\
\hline Stainless steel pan & 0.034 & 0.992 & 0.988 & 0.981 & 0.973 & 0.954 & 0.896 \\
\hline Hammer & 0.069 & 0.961 & 0.958 & 0.943 & 0.942 & 0.936 & 0.916 \\
\hline Glass, $4 \mathrm{~mm}$ & 0.070 & 0.991 & 0.984 & 0.979 & 0.970 & 0.942 & 0.858 \\
\hline Dining room oak furniture & 0.098 & 0.992 & 0.983 & 0.971 & 0.960 & 0.939 & 0.891 \\
\hline Spherical glasses & 0.022 & 0.930 & 0.887 & 0.800 & 0.735 & 0.740 & 0.642 \\
\hline Wallet & 0.069 & 0.996 & 0.991 & 0.985 & 0.978 & 0.965 & 0.938 \\
\hline Torus glasses & 0.027 & 0.771 & 0.767 & 0.617 & 0.532 & 0.606 & 0.504 \\
\hline Cup and saucer & 0.068 & 0.996 & 0.991 & 0.986 & 0.980 & 0.969 & 0.944 \\
\hline \multicolumn{8}{|l|}{ Services } \\
\hline School boarding fees & 0.044 & 0.975 & 0.972 & 0.968 & 0.964 & 0.956 & 0.986 \\
\hline Hourly wage, painter & 0.062 & 0.981 & 0.979 & 0.974 & 0.969 & 0.962 & 0.954 \\
\hline Hourly wage, garage mechanic & 0.106 & 0.999 & 0.999 & 0.998 & 0.998 & 0.997 & 0.996 \\
\hline Annual cable subscription & 0.029 & 0.858 & 0.835 & 0.779 & 0.756 & 0.735 & 0.674 \\
\hline Repair of central heating & 0.059 & 0.995 & 0.994 & 0.990 & 0.987 & 0.981 & 0.972 \\
\hline Hourly wage, plumber & 0.057 & 0.994 & 0.988 & 0.984 & 0.979 & 0.972 & 0.961 \\
\hline Passport stamp & 1.044 & 0.959 & 0.914 & 0.868 & 0.821 & 0.722 & 0.551 \\
\hline Sole meunière & 0.067 & 0.910 & 0.903 & 0.915 & 0.913 & 0.890 & 0.897 \\
\hline Dry cleaning, shirt & 0.051 & 0.996 & 0.993 & 0.991 & 0.989 & 0.983 & 0.955 \\
\hline Pepper steak & 0.052 & 0.998 & 0.996 & 0.994 & 0.992 & 0.988 & 0.970 \\
\hline Permanent wave & 0.072 & 0.999 & 0.998 & 0.997 & 0.996 & 0.995 & 0.993 \\
\hline Domestic service & 0.066 & 0.995 & 0.994 & 0.991 & 0.989 & 0.986 & 0.981 \\
\hline Funeral & 0.055 & 0.884 & 0.881 & 0.858 & 0.853 & 0.892 & 0.867 \\
\hline School lunch & 0.072 & 0.990 & 0.984 & 0.979 & 0.975 & 0.972 & 0.995 \\
\hline Self-service meal & 0.025 & 0.545 & 0.343 & 0.289 & 0.183 & 0.319 & 0.402 \\
\hline Parking spot in a garage & 0.094 & 0.997 & 0.993 & 0.988 & 0.982 & 0.974 & 0.957 \\
\hline Wheel balancing & 0.026 & 0.991 & 0.983 & 0.974 & 0.966 & 0.950 & 0.932 \\
\hline Special beer & 0.069 & 0.988 & 0.983 & 0.984 & 0.981 & 0.982 & 0.967 \\
\hline Aperitif & 0.076 & 0.997 & 0.995 & 0.994 & 0.993 & 0.990 & 0.977 \\
\hline Videotape rental & 0.011 & 0.868 & 0.852 & 0.823 & 0.758 & 0.729 & 0.547 \\
\hline
\end{tabular}




\begin{tabular}{|c|c|c|c|c|c|c|c|}
\hline Product category & $\overline{\div}_{f}$ & $\mathrm{r1}$ & r2 & r3 & r4 & r6 & $\mathrm{r} 12$ \\
\hline \multicolumn{8}{|l|}{ Energy } \\
\hline Eurosuper & 0.091 & 0.980 & 0.953 & 0.929 & 0.900 & 0.841 & 0.650 \\
\hline Gas-Oil & 0.133 & 0.986 & 0.964 & 0.942 & 0.918 & 0.873 & 0.671 \\
\hline \multicolumn{8}{|l|}{ Perishable food } \\
\hline Roast-beef & 0.054 & 0.983 & 0.967 & 0.951 & 0.936 & 0.098 & 0.956 \\
\hline Beef burger & 0.041 & 0.898 & 0.901 & 0.885 & 0.875 & 0.207 & 0.768 \\
\hline Lamb & 0.108 & 0.988 & 0.977 & 0.964 & 0.953 & 0.433 & 0.852 \\
\hline Fresh pork meat & 0.072 & 0.919 & 0.862 & 0.785 & 0.708 & 0.379 & 0.292 \\
\hline Ham & 0.083 & 0.980 & 0.963 & 0.948 & 0.926 & 0.266 & 0.721 \\
\hline Sausages & 0.055 & 0.952 & 0.934 & 0.925 & 0.903 & 0.372 & 0.644 \\
\hline Chicken & 0.132 & 0.987 & 0.972 & 0.953 & 0.933 & 0.840 & 0.715 \\
\hline Rabbit/Game & 0.071 & 0.945 & 0.911 & 0.864 & 0.827 & 0.376 & 0.699 \\
\hline Creme fraiche & 0.030 & 0.980 & 0.967 & 0.954 & 0.933 & 0.480 & 0.742 \\
\hline Milky Desserts & 0.053 & 0.981 & 0.972 & 0.970 & 0.966 & 0.733 & 0.945 \\
\hline Cottage cheese & 0.055 & 0.987 & 0.982 & 0.980 & 0.970 & 0.769 & 0.933 \\
\hline Processed cheese & 0.068 & 0.966 & 0.964 & 0.959 & 0.960 & 0.881 & 0.927 \\
\hline Butter & 0.054 & 0.991 & 0.987 & 0.985 & 0.982 & 0.733 & 0.938 \\
\hline \multicolumn{8}{|l|}{ Non perishable food } \\
\hline Rusks and grilled breads & 0.036 & 0.878 & 0.850 & 0.835 & 0.839 & 0.519 & 0.694 \\
\hline Flour & 0.054 & 0.974 & 0.972 & 0.975 & 0.962 & 0.786 & 0.944 \\
\hline Pasta & 0.210 & 0.997 & 0.991 & 0.984 & 0.977 & 0.935 & 0.900 \\
\hline Canned vegetables & 0.032 & 0.959 & 0.954 & 0.946 & 0.927 & 0.559 & 0.859 \\
\hline Sugar & 0.060 & 0.996 & 0.993 & 0.992 & 0.990 & 0.739 & 0.970 \\
\hline Chocolate & 0.071 & 0.988 & 0.981 & 0.980 & 0.980 & 0.816 & 0.963 \\
\hline Desserts & 0.108 & 0.963 & 0.971 & 0.965 & 0.964 & 0.858 & 0.938 \\
\hline Coffee & 0.055 & 0.939 & 0.847 & 0.741 & 0.641 & 0.478 & 0.054 \\
\hline Tea & 0.085 & 0.981 & 0.982 & 0.981 & 0.975 & 0.961 & 0.959 \\
\hline Fruit juices & 0.034 & 0.912 & 0.918 & 0.897 & 0.889 & 0.473 & 0.871 \\
\hline Whisky & 0.008 & 0.582 & 0.413 & 0.386 & 0.250 & -0.078 & 0.176 \\
\hline Pet food & 0.161 & 0.966 & 0.931 & 0.925 & 0.920 & 0.915 & 0.882 \\
\hline \multicolumn{8}{|l|}{ Non durable goods } \\
\hline Fabrics & 0.065 & 0.100 & -0.183 & 0.084 & -0.161 & -0.089 & 0.612 \\
\hline Men coats & 0.065 & 0.118 & -0.154 & -0.094 & -0.290 & -0.052 & 0.844 \\
\hline Men suits & 0.086 & 0.271 & -0.105 & -0.055 & -0.132 & -0.061 & 0.858 \\
\hline Men trousers & 0.054 & 0.122 & -0.281 & -0.141 & -0.321 & -0.174 & 0.798 \\
\hline Skirt & 0.097 & 0.138 & -0.335 & -0.392 & -0.381 & -0.161 & 0.828 \\
\hline Dress & 0.156 & 0.414 & 0.140 & 0.157 & 0.172 & 0.084 & 0.786 \\
\hline Women trousers & 0.059 & 0.130 & -0.244 & -0.221 & -0.269 & -0.061 & 0.672 \\
\hline Women jacket & 0.113 & 0.284 & -0.009 & -0.003 & -0.008 & -0.080 & 0.794 \\
\hline Children trousers & 0.112 & 0.752 & 0.645 & 0.640 & 0.629 & 0.436 & 0.883 \\
\hline Children suits & 0.224 & 0.481 & 0.392 & 0.390 & 0.440 & 0.356 & 0.545 \\
\hline Men shirts & 0.078 & 0.059 & -0.390 & -0.236 & -0.403 & -0.144 & 0.897 \\
\hline Men socks & 0.043 & 0.075 & -0.050 & 0.009 & 0.126 & 0.051 & 0.329 \\
\hline Men sweater & 0.068 & 0.273 & 0.148 & 0.263 & 0.133 & -0.051 & 0.825 \\
\hline Women sweater & 0.081 & 0.056 & -0.263 & -0.106 & -0.266 & -0.146 & 0.749 \\
\hline Children sweater & 0.091 & 0.430 & 0.150 & 0.147 & 0.177 & 0.134 & 0.704 \\
\hline Babies clothes & 0.112 & 0.083 & 0.027 & 0.273 & 0.107 & 0.074 & 0.474 \\
\hline Men shoes & 0.057 & 0.127 & -0.126 & -0.223 & -0.147 & -0.072 & 0.721 \\
\hline Women shoes & 0.085 & 0.317 & -0.043 & 0.008 & -0.032 & 0.065 & 0.895 \\
\hline Children shoes & 0.084 & 0.126 & -0.185 & -0.201 & -0.236 & -0.024 & 0.795 \\
\hline Blankets and coverlets & 0.045 & 0.186 & 0.134 & 0.432 & 0.203 & -0.071 & 0.792 \\
\hline Fabrics for furniture & 0.046 & 0.548 & 0.476 & 0.516 & 0.461 & 0.012 & 0.581 \\
\hline Batteries & 0.023 & 0.762 & 0.765 & 0.755 & 0.740 & 0.546 & 0.540 \\
\hline Car tyres & 0.053 & 0.951 & 0.948 & 0.936 & 0.930 & 0.898 & 0.840 \\
\hline Musical disks & 0.046 & 0.978 & 0.952 & 0.942 & 0.930 & 0.896 & 0.881 \\
\hline Blank tapes and disks & 0.019 & 0.463 & 0.367 & 0.404 & 0.319 & 0.343 & 0.202 \\
\hline Flowers & 0.058 & 0.853 & 0.538 & 0.205 & -0.093 & -0.446 & 0.923 \\
\hline Children books & 0.073 & 0.940 & 0.939 & 0.921 & 0.925 & 0.915 & 0.916 \\
\hline Newspapers & 0.041 & 0.919 & 0.895 & 0.907 & 0.900 & 0.892 & 0.814 \\
\hline Paper articles & 0.077 & 0.816 & 0.646 & 0.633 & 0.663 & 0.524 & 0.722 \\
\hline eather articles & 0.041 & 0.206 & 0.169 & 0.237 & 0.268 & 0.571 & 0.600 \\
\hline Babies apparel & 0.051 & 0.597 & 0.708 & 0.640 & 0.691 & 0.619 & 0.580 \\
\hline
\end{tabular}

Table D - Statistical properties of the common component $\widehat{f}_{t}-$ France 


\begin{tabular}{|c|c|c|c|c|c|c|c|}
\hline Product category & $\div f$ & $\mathrm{r} 1$ & r2 & r3 & r4 & r6 & $\mathrm{r} 12$ \\
\hline \multicolumn{8}{|l|}{ Durable goods } \\
\hline box-mattress & 0.037 & 0.170 & 0.306 & 0.123 & 0.243 & 0.055 & 0.574 \\
\hline Armchairs and canapes & 0.065 & 0.886 & 0.877 & 0.911 & 0.864 & 0.231 & 0.893 \\
\hline Washing machine & 0.035 & 0.823 & 0.830 & 0.819 & 0.769 & 0.311 & 0.687 \\
\hline Vacuum-cleaner & 0.032 & 0.475 & 0.494 & 0.502 & 0.442 & 0.148 & 0.420 \\
\hline Electrical tools & 0.030 & 0.430 & 0.430 & 0.415 & 0.412 & -0.005 & 0.286 \\
\hline Bicycles & 0.042 & 0.757 & 0.718 & 0.705 & 0.668 & 0.088 & 0.555 \\
\hline Trailor & 0.127 & 0.839 & 0.802 & 0.763 & 0.736 & 0.697 & 0.489 \\
\hline Phone set & 0.132 & 0.985 & 0.984 & 0.983 & 0.978 & 0.976 & 0.949 \\
\hline TV set & 0.226 & 0.952 & 0.953 & 0.956 & 0.941 & 0.926 & 0.886 \\
\hline Video camera & 0.106 & 0.980 & 0.972 & 0.964 & 0.950 & 0.937 & 0.902 \\
\hline Music instrument & 0.049 & 0.857 & 0.821 & 0.849 & 0.813 & 0.817 & 0.724 \\
\hline Electrical razor & 0.085 & 0.672 & 0.675 & 0.690 & 0.673 & 0.721 & 0.565 \\
\hline Jewellery & 0.031 & 0.686 & 0.701 & 0.651 & 0.639 & 0.656 & 0.467 \\
\hline \multicolumn{8}{|l|}{ Services } \\
\hline Shoe repair & 0.061 & 0.787 & 0.797 & 0.781 & 0.727 & 0.244 & 0.392 \\
\hline Water distribution & 0.016 & 0.825 & 0.771 & 0.749 & 0.676 & -0.229 & 0.570 \\
\hline Hourly rate in a garage & 0.094 & 0.996 & 0.992 & 0.990 & 0.989 & 0.988 & 0.980 \\
\hline Car rent & 0.047 & 0.277 & 0.233 & 0.302 & 0.319 & 0.283 & 0.226 \\
\hline Urban transports & 0.081 & -0.147 & 0.074 & 0.046 & 0.058 & -0.016 & 0.067 \\
\hline Moving services & 0.149 & 0.958 & 0.925 & 0.894 & 0.880 & 0.887 & 0.913 \\
\hline Pet care & 0.046 & 0.911 & 0.888 & 0.864 & 0.859 & 0.881 & 0.875 \\
\hline cinemas & 0.041 & 0.497 & 0.431 & 0.421 & 0.449 & 0.432 & 0.341 \\
\hline monument or museum entrance & 0.129 & 0.962 & 0.959 & 0.950 & 0.936 & 0.923 & 0.857 \\
\hline Private high school & 0.026 & 0.759 & 0.736 & 0.714 & 0.753 & 0.712 & 0.783 \\
\hline Private colleges/universities & 0.030 & 0.812 & 0.772 & 0.783 & 0.718 & 0.604 & 0.797 \\
\hline classic lunch in a restaurant & 0.025 & 0.964 & 0.911 & 0.858 & 0.808 & 0.712 & 0.417 \\
\hline coffee and hot drinks in bars & 0.099 & 0.992 & 0.991 & 0.988 & 0.985 & 0.982 & 0.975 \\
\hline beer in bars & 0.067 & 0.984 & 0.983 & 0.978 & 0.980 & 0.976 & 0.963 \\
\hline Non alcoolhic beverage in bars & 0.052 & 0.940 & 0.933 & 0.945 & 0.914 & 0.914 & 0.908 \\
\hline Full-board hotel accomodation & 0.055 & 0.982 & 0.962 & 0.944 & 0.938 & 0.940 & 0.985 \\
\hline men hairdresser & 0.043 & 0.962 & 0.953 & 0.957 & 0.943 & 0.956 & 0.919 \\
\hline women hairdresser & 0.049 & 0.955 & 0.952 & 0.944 & 0.949 & 0.960 & 0.941 \\
\hline Watch/clock repair & 0.212 & 0.944 & 0.910 & 0.872 & 0.844 & 0.765 & 0.563 \\
\hline Day-care center & 0.033 & 0.046 & -0.063 & 0.119 & 0.003 & 0.168 & -0.033 \\
\hline Home insurance & 0.040 & 0.910 & 0.888 & 0.878 & 0.851 & 0.818 & 0.805 \\
\hline Car insurance & 0.022 & 0.814 & 0.409 & 0.209 & 0.231 & 0.141 & 0.062 \\
\hline
\end{tabular}

Table D - Continued 